\title{
Coma and consciousness: paradigms (re)framed by neuroimaging
}

Steven Laureys ${ }^{1 *}$ and Nicholas Schiff ${ }^{2 *}$

*both authors equally contributed to the writing of this paper

1. Coma Science Group, Cyclotron Research Centre and Neurology Department, University and University Hospital of Liège, 4000 Liège, Belgium

2. Department of Neurology and Neuroscience, LC-803, Weill Cornell Medical College, 1300 York Ave., New York, NY 10065, USA

Word count (abstract): 178

Word count (main text): 6941

Figures: 6

References: 159

\section{Correspondence}

$\underline{\text { nds2001@med.cornell.edu or steven.laureys@ulg.ac.be }}$

\section{Keywords}

coma, vegetative state, minimally conscious state, fMRI, PET, consciousness, traumatic brain injury 


\section{Key Points}

- Neuroimaging shows cognition in some patients without motor responsiveness

- This improves clinical and pain management of chronic disorders of consciousness

- It permits selection for thalamic deep brain stimulation and plasticity enhancement

- Awareness depends on frontoparietal \& mesocircuit functional connectivity

- Multi-center studies are offering evidence-based diagnostic and prognostic tests 


\begin{abstract}
The past fifteen years has provided an unprecedented collection of discoveries that bear upon our scientific understanding of recovery of consciousness in the human brain following severe brain damage. Highlighted among these discoveries are unique demonstrations that patients with little or no behavioral evidence of conscious awareness may retain critical cognitive capacities and the first scientific demonstrations that some patients, with severely injured brains and very longstanding conditions of limited behavioral responsiveness, may nonetheless harbor latent capacities for significant recovery. Included among such capacities are particularly human functions of language and higher-level cognition that either spontaneously or through direct interventions may reemerge even at long time intervals or remain unrecognized. Collectively, these observations have reframed scientific inquiry and further led to important new insights into mechanisms underlying consciousness in the human brain. These studies support a model of consciousness as the emergent property of the collective behavior of widespread frontoparietal network connectivity modulated by specific forebrain circuit mechanisms. We here review these advances in measurement and the scientific and broader implications of this rapidly progressing field of research.
\end{abstract}




\section{Measuring consciousness in the severely damaged brain: the need for motor- independent signs of awareness derived directly from brain signals}

\section{A brief history of coma}

The invention of the artificial respirator in the 1950s made it possible for many patients to "survive" their brain damage and led to the redefinition of death based on brain function criteria (i.e., brain death or irreversible coma with absent brainstem reflexes, and to the identification of locked-in syndrome or pseudo-coma (for review see e.g., Laureys, 2005b). It also led to some patients "awakening" from coma (i.e., opening their eyes) but remaining without behavioral signs of awareness or communication. In 1972 Jennett and Plum defined this "artifact of intensive care" as "persistent vegetative state" (VS) (Jennett, 2005); the designation had a mechanistic intent to identify that such patients at the bedside showed only residual autonomous nervous functioning such as sleep-wake, respiration, digestion and thermoregulation originating at a brainstem level. Previously VS had been called "apallic syndrome" (meaning "without cortex", a description we will see below is not correct). "Persistent" VS was used to denote that the condition lasted for more than one month. In 1994, a retrospective study defined the temporal boundaries for irreversibility of VS and proposed the term "permanent VS" (The Multi-Society Task Force on PVS, 1994).

Unfortunately persistent and permanent VS share the abbreviation "PVS" often leading to unwarranted confusion. More recently physicians can refer to VS (which for some can be misguided as "vegetable"-like) using a more descriptive and neutral term "unresponsive wakefulness syndrome" (UWS) (Laureys et al., 2010). However, some authors (including NDS) feel that UWS lacks a mechanistic interpretation and might lead to underspecification and conflation of the newly identified syndrome of significant cognitive function in some patients with the appearance of VS. In 2002, the publication of the operational criteria for 
“minimally conscious state” (MCS) (initially called "minimally responsive state") separated patients showing a range of behavioral signs of awareness up to inconsistent but not reliable communication from the broader category of severe disability (Giacino et al., 2002).

Emergence from MCS was defined by functional communication or functional use of objects.

Figure 1 illustrates how functional neuroimaging studies have, over the past 15 years, progressively changed the spectrum of coma and chronic disorders of consciousness. While some VS patients will irreversibly remain in this condition, we now know that many actually evolve to MCS (Monti et al., 2010a). Since its formal definition nearly 10 years ago (Giacino et al., 2002) a number of authors have questioned the need for disentangling VS from MCS considering both patient groups as hopelessly brain damaged. While such a conflation has always implied a failure to adhere to the strict definitions of VS, as MCS explicitly subcategorizes patients within the overly broad category of severe disability and not a subset of patients that would have fulfilled the definitional criteria for VS. As we will see, recent studies have demonstrated it is important to disentangle both clinical entities as functional neuroimaging have shown differences in residual cerebral processing and hence, conscious perception (Boly et al., 2008a; Coleman et al., 2009; Rodriguez Moreno et al., 2010; Vanhaudenhuyse et al., 2010), as well as important differences in outcome (e.g., Luaute et al.). The clinically heterogeneous entity of MCS can be further subcategorized in MCS+ (describing high-level behavioral responses such as command following or specific responses to linguistic content) and MCS- (describing low-level non-reflex behavior such as visual pursuit, localization of pain or appropriate smiling to emotional stimuli) (Bruno et al., 2011b). After emergence from MCS most patients' cognitive functional remains at least initially below the normative ranges captured by standard neuropsychological test batteries; this range of function has been labeled confusional state and is characterized using quantitative behavioral metrics designed to capture this patient population (Nakase-Richardson et al., 
2008; Sherer et al., 2005). Disambiguating the boundary between MCS and emergence into confusional state, however, has been shown to have ambiguities with respect to developing strict operational criteria (Nakase-Richardson et al., 2008). Finally, we propose a modified application of the term "functional locked-in syndrome" suggested by other authors (Giacino et al., 2009) to characterize patients who unambiguously demonstrate a dissociation between preserved higher cognitive functions only measurable by functional imaging techniques while showing extremely limited motor-responsiveness during bedside clinical testing. This designation should be reserved, however, for patients who show consistent and reliable communication using non-speech and non-gestural communication through direct brain signaling.

\section{The challenge of measuring consciousness}

For neurologists, consciousness can be reduced to arousal (i.e., wakefulness or vigilance) and awareness (i.e., comprising all subjective perceptions, feelings and thoughts) (Posner et al., 2007). Awareness in turn can be divided into "external awareness" (i.e., sensory or perceptual awareness of the environment) and "internal awareness" (i.e., stimulusindependent thoughts, mental imagery, inner speech, daydreaming or mind wandering) (Vanhaudenhuyse et al., 2011). Clinically, arousal is typically measured by examining eyeopening and reproducible command-following to establish proof of (external) awareness. Additionally, the presence of spontaneous or induced non-reflexive behaviors are considered as evidence of (minimal) consciousness (MCS-). The bedside examination of consciousness in severely brain damaged patients, however, is extremely challenging because movements can be very small, inconsistent and easily exhausted, potentially leading to diagnostic errors. This issue is further complicated when patients have underlying deficits in the domain of verbal or non-verbal communication functions, such as aphasia, agnosia or apraxia (Bruno et 
al., 2010a; Majerus et al., 2009; 2005). This problem was highlighted in a study showing that the clinical consensus diagnosis of VS was incorrect in more than $40 \%$ of patients (Schnakers et al., 2009b). Locked-in syndrome patients may also be mistakenly considered unconscious (Bruno et al., 2009a; Laureys et al., 2005; Smart et al., 2008). These studies should urge clinicians to use standardized validated behavioral scales of consciousness when making a diagnosis in these challenging patients. It is currently recommended to use the Coma Recovery Scale - Revised (Giacino et al., 2004) rather than to perform an unstructured clinical assessment (Schnakers et al., 2009a) or to use unsuitable scales such as the Glasgow Coma Scale (Bruno et al., 2011a; Schnakers et al., 2006) when aiming to disentangle VS from MCS. However, given that our clinical measurement of consciousness can be severely compromised when a patient lacks motor responsiveness, functional neuroimaging in principle offers a more direct and objective tool to measure residual cognition in severely brain-damaged patients (Laureys, 2004; Schiff, 2006). In practice, however, as discussed below application of functional imaging techniques to patients with disorders of consciousness are often difficult and ambiguous with respect to resolving diagnostic uncertainty.

Below we discuss the role of positron emission tomography (PET) and functional magnetic resonance imaging (fMRI) in "resting state", passive sensory stimulation and active "command following" and "communication" paradigms in this context. We will see how, over the past 15 years, the old monolithic model inferred from considerations of anatomic pathology and early region-of-interest based FDG-PET imaging have been refined through the use of a variety of new functional neuroimaging analytical tools (e.g., Laureys et al., 2000b; 1999a) and techniques (e.g., H215O PET Menon et al., 1998a; Laureys, 2000 \#2912 and MEG Ribary et al., 1998; Schiff et al., 1999) identifying functional disconnections in the truly vegetative brain and showing variations of cerebral substrate in related conditions, currently being further refined by fMRI (e.g., Bardin et al., 2011a; Monti et al., 2010b), 
quantitative EEG (e.g., Fellinger et al., 2011; Goldfine et al., 2011) and event-related potential studies (e.g., Boly et al., 2011).

\section{Measuring the brain at "rest"}

Fluorodeoxyglucose positron emission tomography (FDG-PET) studies have shown a global and massive decrease in brain metabolism in VS (De Volder et al., 1990; Levy et al., 1987; Rudolf et al., 1999; Tommasino et al., 1995). Voxel-based statistical analytical tools next permitted to recognize not only global or a priori defined region-of-interest changes in brain function but more detailed data-driven regional differences and more importantly assessed changes in effective connectivity when VS was compared with healthy conscious waking. This permitted to identify an impaired widespread fronto-parietal network encompassing midline (i.e., anterior cingulate/mesiofrontal and posterior cingulate/precuneus) and lateral (i.e., prefrontal and posterior parietal) associative cortices (Laureys et al., 1999a; 1999b; Lull et al., 2010). These observations have since been confirmed (Beuthien-Baumann et al., 2003; Bruno et al., 2010b; Juengling et al., 2005; Nakayama et al., 2006; Silva et al., 2010). The functional connectivity studies showing that VS is a cortico-cortical (Laureys et al., 2000b; 2002b; 1999a) and thalamo-cortical (Laureys et al., 2000b) disconnection syndrome led to the hypothesis that consciousness is an emergent property of frontoparietal connectivity (Baars et al., 2003; Laureys, 2005a). Functional neuroimaging studies on conscious perception in healthy volunteers (Dehaene, 2000; Rees et al., 2002) as well as data obtained in sleep (for review e.g., see Maquet, 2010) and general anesthesia (for review e.g., see Boveroux et al., 2008) also corroborates this theory.

Development of "consciousness classifiers" for clinical use has followed these observations with new studies showing evidence that automatically assessing the functional 
integrity in this frontoparietal network and calculating a probability of being VS or conscious but "locked-in" can be based on objective FDG-PET data (Phillips et al., 2010). Structural MRI studies such as diffusion tensor imaging also permit to quantify lesions to the brain's white matter tracts in severe brain injury, often invisible to conventional radiological approaches (Newcombe et al., 2010) and may help differentiating VS from MCS (2010a). FDG-PET imaging was also employed to help clinicians to better understand possible clinical signs of (un)consciousness. Bruno et al (2010b) showed that anoxic VS patients with or without visual fixation presented an identical impairment of frontoparietal network metabolism and connectivity, concluding that visual fixation is not necessarily a clinical sign reflecting conscious awareness. Resting state fMRI studies have shown that the midline frontoparietal "default mode" connectivity, thought to reflect internal awareness (i.e., spontaneous thoughts, inner speech and mind wandering) (Boly et al., 2008b; Soddu et al., 2009; Vanhaudenhuyse et al., 2011), disappears in brain death (Boly et al., 2009) and decreases in VS (Boly et al., 2009; Cauda et al., 2009; Vanhaudenhuyse et al., 2010) (table 1). MCS patients showed an intermediate pattern with a higher functional connectivity of the posterior cingulate/precuneus area as compared to unresponsive patients (Vanhaudenhuyse et al., 2010) - confirming the above-discussed FDG-PET results. Interestingly, the authors also showed a linear correlation between behavioral CRS-R total scores and "default mode network" connectivity. The study of VS patients who subsequently recovered offered an additional causal link between consciousness and the functional integrity of this long-range frontoparietal network - pointing to the role of non-specific (central intralaminar) thalamic projections in the support of these large-scale distributed cortico-cortical connections (Laureys et al., 2000b). These conclusions were strongly supported by the Schiff et al (2007) discussed below who successfully performed deep-brain stimulation of these diffusely 
projecting thalamic nuclei improving behavioral responsiveness and awareness of a posttraumatic MCS patient.

\section{INSERT TABLE 1}

\section{From “Activation" studies to passive stimulations}

Menon et al. (1998b) first claimed to have demonstrated residual 'cognition' in a VS patient using functional neuroimaging techniques. In their study, a VS patient had differential ${ }^{15} \mathrm{O}$ labeled water PET responses in extrastriate higher-order visual cortical regions when presented with structured visual images and scrambled versions of the same images. The inference that such isolated cerebral activations demonstrated cognition was controversial (Menon et al., 1999; Schiff and Plum, 1999) and to date, as discussed below, passive paradigms producing higher-level cortical activations remain ambiguous evidence for level of awareness or cognitive function, if the term is reserved for an element of intentionality of perception.

Table 2 summarizes functional neuroimaging activation studies using ${ }^{15} \mathrm{O}$ labeled water PET and fMRI to identify blood flow increases in response to passive external stimulation in severely brain-damaged patients. The first PET activation studies showed that for most typical VS patients a "low level" cortical activation encompassing primary auditory (Boly et al., 2004; Laureys et al., 2000a; Owen et al., 2002; Schiff et al., 2002), somatosensory (Boly et al., 2008a; Laureys et al., 2002b) or visual (Giacino et al., 2006; Menon et al., 1998a) cortices can be observed. fMRI and magnetoencephalography (MEG) studies have corroborated these findings (Bekinschtein et al., 2005; Coleman et al., 2007; Fernandez-Espejo et al., 2008; Heelmann et al., 2010; Rousseau et al., 2008). As compared to VS, functional neuroimaging studies in MCS showed a higher level of functional segregation 
(i.e., more widespread activation) and functional integration (i.e., more functional long range connectivity with frontoparietal "awareness" networks) for both auditory (Boly et al., 2004) and noxious processing (Boly et al., 2008a). The latter study, showing evidence of residual pain perception in MCS has obvious clinical consequences. In this study MCS patients demonstrated activation of the entire 'pain matrix', a distributed cortical and subcortical network linked to pain perception that importantly included the anterior cingulate and insular areas thought to be important in the affective emotional perception of pain (Kupers et al., 2005). These findings should strongly influence physicians to systematically use analgesic agents in MCS patients, even if (by definition) they cannot communicate their sensations (Schnakers et al., 2010). A recently proposed "pain scale" specifically developed for use in disorders of consciousness now permits monitoring of nociception/pain and guidance for the adaption of analgesic treatment (Schnakers et al., 2010).

Functional neuroimaging studies have also aimed to address the question whether severely brain-damaged patients perceive emotions. A series of studies have illustrated that intense or emotionally relevant stimuli induce higher-level activation in MCS (for review (Laureys and Boly, 2007). In the auditory modality, these studies have used presentation of meaningful stories told by a relative (Bekinschtein et al., 2004; Schiff et al., 2005) or autoreferential stimuli such as the patient's own name (Di et al., 2007; Laureys et al., 2004b; Qin et al., 2010). The latter studies, for example, show activation of midline structures (i.e., anterior cingulate/mesiofrontal and posterior cingulate/precuneus) known to be involved in internal or self-consciousness (Laureys et al., 2007). Qin et al. (2010) reported a linear correlation between activation of the anterior cingulate cortex and the level of consciousness as quantified by coma recovery scores.

\section{INSERT TABLE 2}




\section{Mental imagery tasks to show fMRI based command following and communication}

The most important advance in the use of neuroimaging of disorders of consciousness has been the development of novel paradigms that provide unambiguous imaging evidence of volition and awareness. These studies have led to the identification of new and likely specific syndrome. Owen et al. (2006) reported a collaborative study between the Cambridge and Liège groups that demonstrated a post-traumatic patient diagnosed in VS who could follow commands when assessed using a novel fMRI paradigm thus contravening her clinical examinations and apparent diagnosis. When the patient was asked to imagine playing tennis, activation was observed in the supplementary motor area. The instruction to imagine moving around in her house resulted in parahippocampal activation. These specific activations patterns were not different from those previously observed in a cohort of healthy volunteers (Boly et al., 2007). Similar "active" or "command following" paradigms have been tested in severe brain-damaged patients with different technologies such as fMRI, EEG, event related potentials or electromyography (see table 2). In a next step, Monti and Vanhaudenhuyse et al. (2010b) adapted this methodology to establish evidence of fMRI-based communication in a single subject with the presumptive diagnosis of VS and thus provided the first proof-ofconcept for a neuroimaging based communication in an otherwise unresponsive patient. It should be stressed that the absence of command-related brain activation (i.e., a negative result) does not permit to make strong claims about the absence of consciousness. Similarly, the presence of fMRI based command following signals does not guarantee the potential for the patient to use these signal for a reliable and consistent communication system. Bardin et al. (2011b) demonstrated two examples where fMRI based command following did not lead to communication using this signal. In one of these two patients, the investigators provided test-retest confirmation of the dissociation of positive fMRI command following but negative 
fMRI communication. Variations on the Monti and Vanhaudenhuyse et al. (2010b) paradigm in this allowed for intermediate responses to be generated so that patients may attempt but not complete or so delayed responses adding to the complexity of assessment of communication capacities (Bardin et al., 2011a; 2011b). "Active” fMRI paradigms in patients with disorders of consciousness are now being used with various methodologies, asking patients to: "look at a screen and silently name the objects as they appear" (resulting in language network activation) (Rodriguez Moreno et al., 2010); "move the hand" (resulting in premotor cortex activation) (Bekinschtein et al., 2011) and "imagine swimming" (resulting in supplementary motor area activation).

Concurrently, cheaper and portable techniques using event related potential, quantitative EEG, or electromyography "active" paradigms have been developed to detect possible signs of command following not assessable by clinical behavioural examination. Schnakers et al. (2008b) presented a list of names (including the own name) and showed that some MCS patients, when instructed to count a target name, showed an increase in amplitude of the "P3" potential (known to vary with attention) (none of VS patients could do the task). This paradigm also permitted to detect consciousness in a rare case of total locked-in syndrome (i.e., characterized by complete immobility including eye movements), behaviorally diagnosed as comatose (Schnakers et al., 2009a). This methodology was also adapted by asking patients to count the number of deviant trials in an auditory oddball series (Bekinschtein et al., 2009a). Goldfine et al. (2011) have developed quantitative EEG methods to implement the methodologies of Owen et al. (2006) in fMRI for command following and have demonstrated similar variations in linking behavioral evaluations to directly measured brain-signal evaluations of command following seen in the Bardin et al. (2011b) study. Finally, Bekinschtein et al. (2008) could show subclinical movements by means of electromyography recordings, when patients were asked to move their hand. 


\section{INSERT TABLE 3}

Table 3 offers an overview of the fMRI, EEG, evoked potential and EMG studies aiming to show signs of consciousness and communication not accessible by bedside behavioral examination. The absence of functional brain activity in response to the instructions can have many possible causes, ranging from test-dependent technological (corrupted signals due to movement or other artifacts often encountered in these patients and especially troublesome in fMRI experiments - e.g. see (Soddu et al.)) to patient-dependent fluctuations in arousal (spontaneous or medication related), perceptual sensory or cognitive insufficiencies (the discussed mental imagery, motor or attentional tasks indeed require preservation of different cognitive processes such as visual, auditory, language and working memory functions). When negative results do not necessarily reflect proof of the absence of consciousness, positive results are informative and relatively easy to interpret as a proof of consciousness.

The neurological community at present has no diagnostic category for patients showing only signs of consciousness or communication on ancillary fMRI or evoked potential studies such as the ones discussed above (2010b; 2006). Patients who can perform motor imagery tasks on command or use these complex mental imagery tasks to communicate, cannot be considered as VS or even MCS. For patients who ultimately demonstrate consistent and reliable communication using solely adjunctive technologies we here propose to call this condition "functional locked-in syndrome", following the suggestion of this term by other authors (Giacino et al., 2009) but delimits the use to recognize that there is uncertainty when cognitive level cannot be measured and evidence for patients who can only demonstrate command following using the technique. Command following using fMRI mental imagery 
nonetheless underscores a marked dissociation between an extreme behavioral motor dysfunction and preserved higher cognitive functions identified by functional imaging techniques and likely identifies patients near the level of functional locked-in state even if a failure of communication using the method should preclude their labeling with this term.

In conclusion, some patients who awaken from their coma may fail to show any behavioral sign of awareness (VS), or they may remain unable to communicate (MCS). The clinical management of these disorders of consciousness remains very challenging, but technological advances in neuroimaging are now offering new ways to improve our diagnosis. It is an exciting time as the behaviorally defined gray zones between the different disorders of consciousness in the clinical spectrum following coma are being challenged by increasingly powerful imaging technology. This short review illustrates how increasing our understanding of the neural correlates of consciousness is helping clinicians doing a better job in terms of diagnosis, prognosis and finally, we hope, treatment and drug development (e.g., the use of functional imaging in demonstrating the effect of amantadine (Schnakers et al., 2008a) and methylphenidate (Kim et al., 2009) on “consciousness"-networks). Increasing evidence from functional neuroimaging and electrophysiology demonstrates some residual cognitive processing in a subgroup of patients. The current challenge remains to continue translating this research from the bench to the bedside - within a well-defined ethical frameworks (e.g., see Fins et al., 2008a; Fins and Schiff, 2010; Schiff et al., 2009). Only well-controlled large multi-center neuroimaging and electrophysiology studies will enable to identify which paraclinical diagnostic or prognostic test is necessary, at any given time, for our routine evidence based assessment of individuals with chronic disorders of consciousness.

\section{Building a scientific model of recovery of consciousness: linking insights from spontaneous recovery and the impact of effective interventions}


Building on these new measurements and insights gained into the physiology of the vegetative brain from studies carried out the late 1990s and early 2000s, investigations began to focus on characterizing differences in brain function between VS patients and patients who at first glance looked similar, those in MCS (Laureys et al., 2004a). These early observations provided hints of significant functional variation in the brains of some patients fulfilling the clinical criteria for the diagnosis of vegetative state (Menon et al., 1998a; Owen et al., 2002; Schiff et al., 1999; Schiff and Plum, 1999; Schiff et al., 2002); however, later studies that provided direct comparisons of functional neuroimaging in VS and MCS patients demonstrated several fundamental differences separating these patient populations and normal subjects that provided new insight into possible differences in underlying brain mechanisms.

Unlike VS patients, patients with behavioral assessments indicating levels of function consistent with MCS demonstrated evidence of functionally connected networks as demonstrated by response to different types of sensory stimuli including passive simple auditory, somatosensory and complex language stimuli. In MCS patient such stimuli produced activation of large-scale brain network responses across multiple cortical regions beyond the primary sensory cortices (Boly et al., 2004; Coleman et al., 2007; Hirsch et al., 2001; Laureys et al., 2004b; Schiff et al., 2005). Although MCS patients demonstrated evidence of functionally connected large-scale networks similar to normal subjects with clear variations in the quality of response and resting metabolic patterns, significant differences in the volume of overall and regional brain activation measured using fMRI were seen identified, with decreased blood-oxygen dependent level signal seen in MCS patients compared with the normals. In addition, novel stimulus selective response patterns appeared in some MCS patients. Passive language stimuli presented as normal speech or in timereverse produced wide dissociation of large-scale network activation in MCS patients suggesting a fundamental difference in resting brain state compared with normal subject 
testing using the same paradigm (Hirsch et al., 2001; Schiff et al., 2005). Quantitative studies of resting cerebral metabolism in MCS patients also showed significant differences from normal subjects with resting global metabolic rates measured near $\sim 50 \%$ of normal (Laureys et al., 2004b; Schiff et al., 2005); these values are comparable with values found in pharmacologic coma and vegetative state. Taken together, with the studies of passive stimuli in MCS patients, these findings suggested that relatively intact cerebral integrative processes remained, but like the unreliable behavioral responsiveness seen in these patients, neuronal responses were similarly unstable.

Important differences between MCS and normal subject responses were not only identified and seen in the quality of overall network responses in both the absolute level of BOLD activation in response to stimuli (Boly et al., 2008a; Laureys et al., 2004b; Rodriguez Moreno et al., 2010; Schiff et al., 2005; Vanhaudenhuyse et al., 2010) but also in the overall resting metabolism of a regional selective zone in the mesial parietal regions of the brain as assessed using FDG-PET separated MCS from normal subjects (Laureys et al., 2006; 1999b). In a series of related studies, Laureys et al. have identified a grading of recovery of metabolism and functional connectivity of cortical regions within the posterior medial complex (mesial parietal cortex, precuneus, posterior cingulate, retrosplenial cortex) (Vogt et al., 2006 ; Vogt and Laureys, 2005). These brain regions are known to have a very high resting metabolic rate that dominates the pattern of resting brain activity and may represent a 'default' state as proposed by Raichle (2007). Similarly, functional correlations of resting blood-oxygen level dependent signals arising within these cortical regions define a 'default mode' network in resting functional magnetic resonance imaging studies. These observations compare directly with other demonstrations that large frontal-parietal association cortex regions show decreases in functional connectivity and relative blood flow in unconscious 
brain states including anesthesia and non-convulsive seizures (reviewed in Brown et al.; Laureys, 2005a).

Several independent lines of evidence have also long implicated the functional integrity of mesial frontal, midbrain and central thalamic systems in the graded level of recovery of consciousness seen across patient after an initial coma (reviewed in Posner et al., 2007). Included are long-standing observations that selective, bilateral lesions of the central midbrain and thalami can produce enduring disorders of consciousness. Although many patients show slow recovery from such injuries (Katz et al., 1987; van Domburg et al., 1996), persistent fluctuations in behavioral responsive are typical (Stuss et al., 1988; Van Der Werf et al., 1999) and similar to fluctuations seen in MCS patients with non-selective patterns of brain injury. Multi-focal brain injuries are known to have a disproportionate impact on the integrity of the central thalamus (Maxwell et al., 2006) along a continuum with chronic vegetative state associating with marked neuronal loss across central thalamic nuclei (Kinney et al., 1994; Maxwell et al., 2006). Based on the evident potential for recovery after enduring disorders of consciousness in some MCS patients and the impact of non-selective brain injuries on deafferenting these critical thalamic regions, Schiff (1997) proposed a strategy for patient selection based on fluctuations in conscious behaviors and selection of specific regions of the central thalamus for electrical stimulation. Supporting this approach, Laureys et al. (2000b) found evidence that spontaneous recovery from VS to MCS or higher levels of function correlated with increased functional connectivity between the intralaminar regions of the thalamus and the prefrontal cortices and restoration of metabolism in prefrontal cortex and central thalamus.

A proof-of-concept study demonstrated that despite long-standing MCS level function, a patient 6 years after injury recovered multiple cognitively-mediated behaviors after placement of bilateral central thalamic deep brain stimulation electrodes (Schiff et al., 2007). 
The patient selected was one of two MCS first demonstrated to retain large-scale cerebral network response to passive language stimulation despite markedly depressed rates of global metabolism as shown in figure 5. In this patient central thalamic DBS restored arousal regulation and promoted improved behavioral responsiveness; the patient had remained unable to communicate reliably via eye-movements or gestures, feed orally, organize functional movements, or speak during the 6 year period prior to the study. Figure $5 \mathrm{~b}$ illustrates the bilateral placement of the electrodes in the central thalamus, and Figure 5c graphs the main results of the intervention. Behavioral baseline evaluations showed no change in behavioral responsiveness as compared to functional levels measured more than 2 years before the start of the trial. Across the trial quantitative behavioral assessments demonstrated significant improvements when compared against the 6 month pre-stimulation baselines that were unambiguously statistically linked to the deep brain stimulation intervention (see Schiff et al., 2007). Importantly, observed carryover effects of improvements from the ON to the OFF state were also identified as seen in the marked differences in the OFF state baselines during the formal trial of the intervention that had accumulated during a five month titration period of exposure to brain stimulation (see Supplementary Data from Schiff et al. 2007 and discussion below).

\section{Modeling consciousness}

An organizing mesocircuit model provides an economical explanation of the vulnerability of the anterior forebrain in the setting of widespread deafferentation and neuronal cell loss associated with a variety of severe brain injuries that produce unstable levels of behavioral responsiveness associated with MCS and patients just past the border of MCS in confusional state (see Figure 6). The primary consequence of broad deafferentation following either diffuse multifocal patterns of corticothalamic disconnection or bilateral 
injuries to afferent pathways providing forebrain arousal emanating or passing through the upper brainstem and central regions of the thalami is disfacilitation, a passive hyperpolarization of neurons that reduces their firing rates (Schiff, 2010). Experimental studies demonstrate that powerful consequences on background firing rates occur even with disfacilitation producing only modest reductions in cerebral blood flow (Gold and Lauritzen, 2002). The common denominator in all disturbances of consciousness following severe brain injuries may be the circuit-level consequences of a broad decrease in background synaptic activity and excitatory neurotransmission Within the anterior forebrain circuit as illustrated in Figure 6, the medium spiny neurons of the striatum have a key role as a gate via their inhibitory projections to the globus pallidus interna which in turn inhibit the central thalamus. The thalamocortical projections from the central thalamus strongly innervate both the frontal cortex and the striatum (see refs for further details Schiff, 2010). This mesocircuit model efficiently predicts both the impact of central thalamic deep brain stimulation and a variety of specific pharmacological interventions known to be in some cases effective in improving behavioral responsiveness in severely brain-injured patients. Among these other interventions several observations note the well-known response to dopaminergic agents of severely braininjured patients. Schnakers et al. (2008a) showed specific changes in frontoparietal metabolism induced by amantadine (Figure 6B). Consistent with the proposed model, dopaminergic facilitation of the output of the medium spiny neurons or direct modulation of mesial frontal cortical neurons would explain the restoration of anterior forebrain activity within the loop connections of the frontal cortex, striatum, pallidum and central thalamus. Perhaps the most counterintuitive set of observations of behavioral improvements associated with pharmacological interventions in MCS patients accounted for by the model is the quite paradoxical phenomenon of marked behavioral facilitation occasionally observed with administration of the sedative agent zolpidem (a non-benzodiazepine hypnotic that potentiates 
GABA-A alpha 1 receptors, (Brefel-Courbon et al., 2007; Clauss and Nel, 2006; Schiff and Posner, 2007). A correlation of modeling and physiological studies demonstrate the EEG shows elements of normalization with zolpidem which are strongest in patient measurements over the anterior forebrain, see Figure 6C (Schiff and Laureys unpublished, Drover et al., 2010; Williams et al., 2009).

\section{A common model for changes in precuneus/posterior medial parietal complex and anterior forebrain mesocircuit during recovery of consciousness.}

Both anatomical and physiological studies demonstrate a strong link between the central thalamus and the posterior medial cortical regions. Track tracing studies in non-human primates identify the intralaminar thalamic nuclei targeted by the deep brain stimulation in the study shown in Fig 6 as providing a broad innervations of all components of the posterior medial complex of the parietal lobe (Buckwalter et al., 2008) whereas each individual region has stronger point to point connections with other individual thalamic nuclei. A recent human anesthesia study found that both the thalamus and precuneus showed selective significant decreases regional blood flow during anesthetic coma compared with wakeful baseline and notably increase blood flow selectively with recovery of consciousness achieved during stable anesthesia with administration of system cholinergic agonist (Xie et al., 2011). In the human thalamus, the central lateral nucleus and surrounding paralaminar regions receive the heaviest innervations of both brainstem and basal forebrain cholinergic systems and project widely to supergranular cortical regions (Heckers et al., 1992; Van der Werf et al., 2002). Of note, activation of midline central regions by evoked response from the left DBS electrode, which generated bilateral patterns of activation, was demonstrated for patient shown in Figure 5 (see Supplementary data from Schiff et al. 2007). This pattern of evoked cerebral activity is consistent with projections from the central thalamus to medial parietal cortical regions. 
Taken together, these lines of evidence support a linkage of the observed patterns of increased metabolic activity and functional connectivity across both the anterior forebrain and medial parietal cortex via increased thalamocortical activation through the central thalamus that has broad and highly effective projections.

\section{Slow structural modifications of the brain during recovery from disorders of consciousness.}

Late recovery of function following severe brain injury may be associated with structural changes in the brain. Voss et al. (2006) demonstrated evidence of ongoing structural modifications using diffusion tensor magnetic resonance imaging (DTI), in a man who at age 40 spontaneously recovered full expressive and receptive language, after remaining in MCS for 19 years following a severe traumatic brain injury. DTI quantifies the anisotropy of proton diffusion and thus is a proxy for axonal fiber integrity. Despite DTI evidence of widespread white matter injury, a longitudinal assessment of this patient identified regions that showed significant change in measured fractional anisotropy over a 18 month time period beginning over 20 years following injury. Notably, markedly increased fractional anisotropy was present in the mesial parietal cortices and nearby cortical regions that reduced in the second study. These regions showed high metabolic activity in FDG-PET studies obtained at both time points and suggest that recovery of function may have correlated with activity and structural remodeling in these regions that as noted above play an important in the baseline resting brain. Importantly, similar changes were seen in the patient midline cerebellum that directly correlated with observed clinical improvements in motor control between the two studies. Supporting these findings a prospective cohort study of severely brain injured patients followed for a year following initial injury, found very similar changes in DTI measured fractional anisotropy in the patients who recovered neurological function including evidence of increases in fractional anisotropy to supranormal levels in some brain regions (Sidaros et 
al., 2008). Other studies have suggested that differences in DTI measured quantities may separate levels of recovery from vegetative state to MCS (Fernandez-Espejo et al., 2010a).

Dynamical changes in brain function can occur over surprisingly long time intervals in MCS. The proposed circuit mechanisms discussed above provides a mechanism by which a significant 'switch-like' change in overall forebrain activation may occur at a threshold allowing release of increasing thalamocortical/striatal outflow but do not account for evidence of slow continuing improvements evident in carryover effects associated with deep brain stimulation (Schiff et al., 2007) or pharmacological interventions (Brefel-Courbon et al., 2007; Schnakers et al., 2008a). These observations require other mechanisms that in addition to axonal regrowth likely include changes in synaptic efficacy, pools of available receptors and other fundamental alterations in the cellular profile of individual neurons over time as brain state changes.

In summary, it appears that the most fundamental new insights into brain mechanisms underlying human consciousness derived from studies of severe brain injuries to date are related to large-scale patterns of brain activity essential to support the conscious state. Two main patterns have emerged from studies as reviewed above: 1) a strong link of resting metabolism in medial parietal cortex/posterior medial complex (precuneus, retrosplenial, posterior cortex) indexing levels of functional recovery across disorders of consciousness from coma to emergence from minimally conscious state, and 2) a key role for the central thalamus in regulation of anterior forebrain activation ranging from switch-like reactivation to more graded contributions correlated with behavioral responsiveness. Both mechanisms are likely reflections of one common dynamical process of progressive increases in neuronal activity within the corticothalamic systems as consciousness recovers and specific markers of the essential large-scale mesocircuits that must reestablish baseline patterns of activity for brain-injured patients or anesthetized normal subjects to regain consciousness (Boveroux et 
al., 2010; Brown et al.; Noirhomme et al., 2010; Schrouff et al., 2011). In addition, new studies are providing insight into detailed dynamics associated with mental activities and evidence that changes in internal brain dynamics may be consistent with conscious awareness and higher level brain function after severe brain injury thus enlarging the set of observations to be accounted for by neuroscientific models of consciousness.

\section{Next steps and broader implications}

It is an exciting era for the field of brain injury and disorders of consciousness. The gray zones between the different clinical entities in the spectrum following coma are beginning to be better understood and defined by the increasingly powerful neuroimaging technologies. As we have here briefly discussed a yet to be determined minority of patients who are currently considered to be "vegetative" or unresponsive, show fMRI or EEG/ERP based signs of consciousness that are inaccessible to clinicians' motor-response dependent behavioral assessment. These ever improving technological means are changing the existing clinical boundaries and will permit some "non-communicative" and locked-in (Bruno et al., 2009b; Gosseries et al., 2009; Laureys et al., 2005) patients to correspond their thoughts and wishes and control their environment via non-motor pathways. It is clear from this overview that our understanding of consciousness and disorders of consciousness after coma is currently witnessing a significant paradigm shift (Laureys and Boly, 2008; Owen et al., 2009).

For clinical medicine, the directions are fairly clear. The most important challenge now is to move from the above discussed single case reports and small cohort reports to large multi-centric studies further addressing the sensitivity and specificity of the discussed "hightech" ancillary neuroimaging or electrophysiological tools. Moreover, these early studies are also showing the potential prognostic value of the technique (Coleman et al., 2009; Di et al., 
2008). Indeed, VS with absent or low-level brain activation (i.e., the majority of the studied cases) have lower chances of subsequent recovery as compared to those with higher-level activation (i.e., activation extending to associative multimodal cortices). The latter pattern of activation is often (albeit not always) encountered in MCS patients (Zhu et al., 2009). In addition to MRI diffusion tensor imaging (Fernandez-Espejo et al., 2010b; Tollard et al., 2009; Tshibanda et al., 2010; Tshibanda et al., 2009), functional MRI also seems to herald prognostic information (Coleman et al., 2009; Di et al., 2008) showing that VS patients with absent or "low-level" sensory cortex activation may have worse outcomes as compared to patients showing "higher-level" of associative cortex activation. Similarly, electrophysiological studies have aimed to predict outcome; a recent standardized classification method of routine "resting state" EEG showed a correlation at the group level with 3-months outcome measures (Bagnato et al., 2010). In a retrospective study of "resting state" routine EEG from 50 VS patients, Babiloni et al. (2009) showed that increased alpha wave power correlated with recovery at 3-months. Cologan et al. (2010) recently reviewed the literature on sleep-wake EEG recordings, discussing the positive predictive value of sleep "spindle" waves for recovery of consciousness (Landsness et al., 2011). Using evoked potentials and "passive" auditory oddball stimuli, the presence of a "P300" wave to rare stimuli correlated with recovery of consciousness in 34 patients with post-traumatic VS (Cavinato et al., 2009). Finally, the presence of Pavlovian eye-puff trace conditioning has been proposed as a new marker of learning, correlating with recovery (Bekinschtein et al., 2009b). While it is clear that although not all patients harbor significant reserve capacities, many do and those half-way recovered will very likely benefit from more systematic and generalizable knowledge concerning the recovery process. In order to propose such validated evidence based algorithms specifying when and what investigation needs to be performed in 
which patient for diagnostic or prognostic purposes, much more research efforts and funding are required to achieve these goals.

For the science of human consciousness the next steps are more likely to surprise than be strongly anticipated given the complexity of the problem. As more sophisticated measurements of brain function are applied to patients with near normal cognitive states who cannot speak or gesture our measurements will continue to confront our conceptual limitations of how such capacities are formed in the brain. As noted above, many new and innovative paradigms and analyses are appearing expanding the database and giving additional insights into the problem. In a not so far future, it is possible that real-time fMRI based communication (Sorger et al., 2009) or evoked potential brain computer interfaces will be used to address important clinical and ethical questions such as feeling of pain and discomfort (Laureys and Boly, 2007). On the other hand, recent demonstrations that the injured brain may signal accurate communication with distinct patterns of basic brain responses compared to those of normal subjects (e.g. delayed hemodynamic signals (Bardin et al., 2011a; 2011b); or EEG signals multiplexed in to novel frequency patterns (Fellinger et al., 2011; Goldfine et al., 2011), will challenge the easy translation of these techniques developed to communicate with cognitively intact subjects. Moreover, it is yet unclear whether in the absence of nuanced initiation of speech or gesture, whether the quality of such communications will ever reach a standard acceptable to adjudicate clinical and legal judgments (Fins and Schiff, 2010).

Finally, this evolving field of work sets several broad and important challenges for medical ethics. As each discovery as come forward a marked ethical reframing continues occur with the shifting models of recovery, diagnosis and prognosis (Fins, 2009a, b). These frames will continue change as these studies evolve and require that policies for patients with disorders of consciousness keep up with the times. Moreover, for the group of patients with 
capacity to communicate these scientific discoveries bear on their fundamental rights for accurate diagnostic assessments and the basics of clinical care (Fins, 2009b; Fins et al., 2008b) 


\section{Author contributions}

SL and NDS equally contributed to the review plan and writing of the article.

\section{Conflict of interest}

SL has no conflict of interest.

\section{Role of the funding source}

SL and NDS are supported by the James S. McDonnell Foundation. SL is Senior Research Associate at the Belgian Funds for Scientific Research (FRS) and is funded by the European Commission. NDS is funded by the National Institutes of Health (NINDS, NICHD). 


\section{Figures}

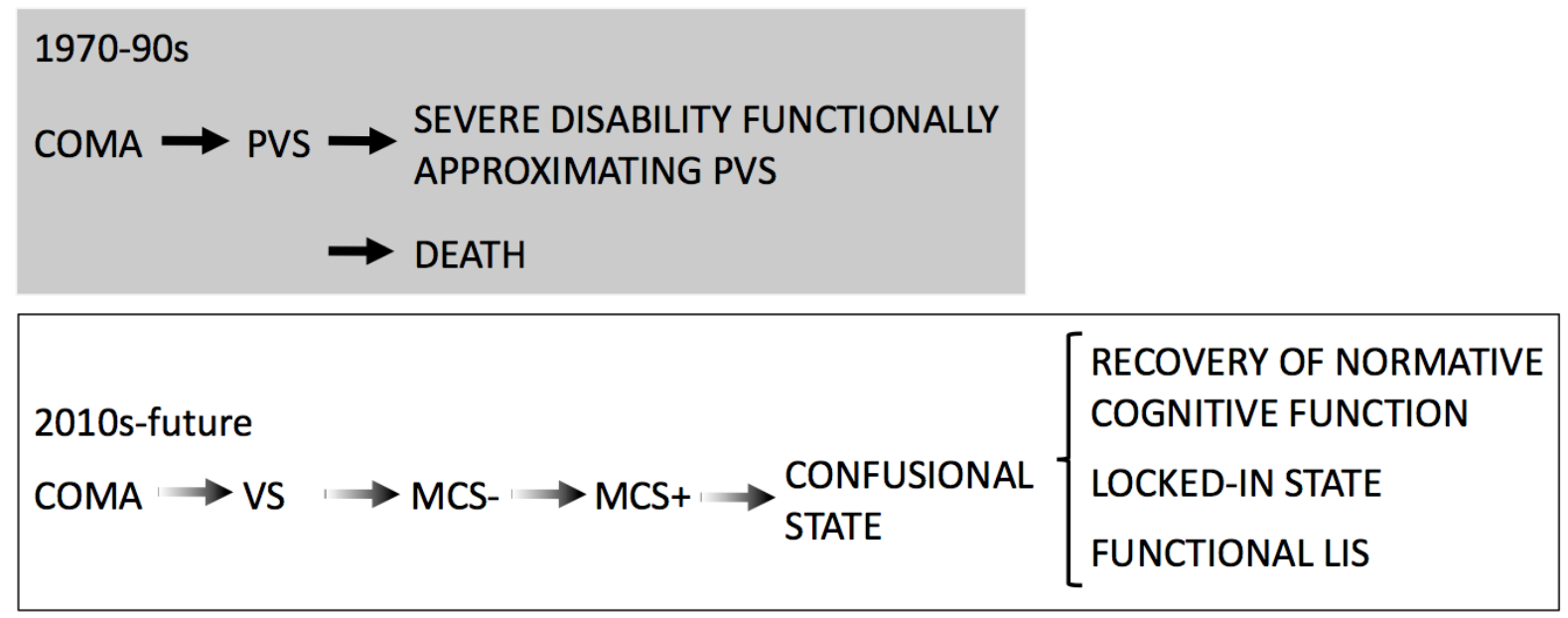

Figure 1 Changing view on chronic disorders of consciousness.

The monolithic way of looking at severe brain damage (in grey) is being replaced by a more graded nosology (in white) based on quantitative behavioral assessments and functional neuroimaging methods. The simplified graph illustrates that patients in erroneously diagnosed as "vegetative/unresponsive wakefulness" state (VS), itself a syndrome previously considered to be uniformly hopeless, are now often being identified as within the subcategory of severe disability as in "minimally conscious state", with further refinement suggested by some authors as MCS- (i.e., showing non-reflex movements), MCS+ (i.e., with fluctuating command following shown by clinical testing) (Bruno et al., 2011b). Emergence from MCS is typically followed by entry into confusional state with further recovery depending on integrity of motoric function leading to normative cognitive function which may co-exist with nearly no motor output (locked-in state) or absolutely no motoric function "functional locked-in" (i.e., with consistent communication via innovative functional neuroimaging techniques-for which at present there is no demonstrated example in the published literature). 

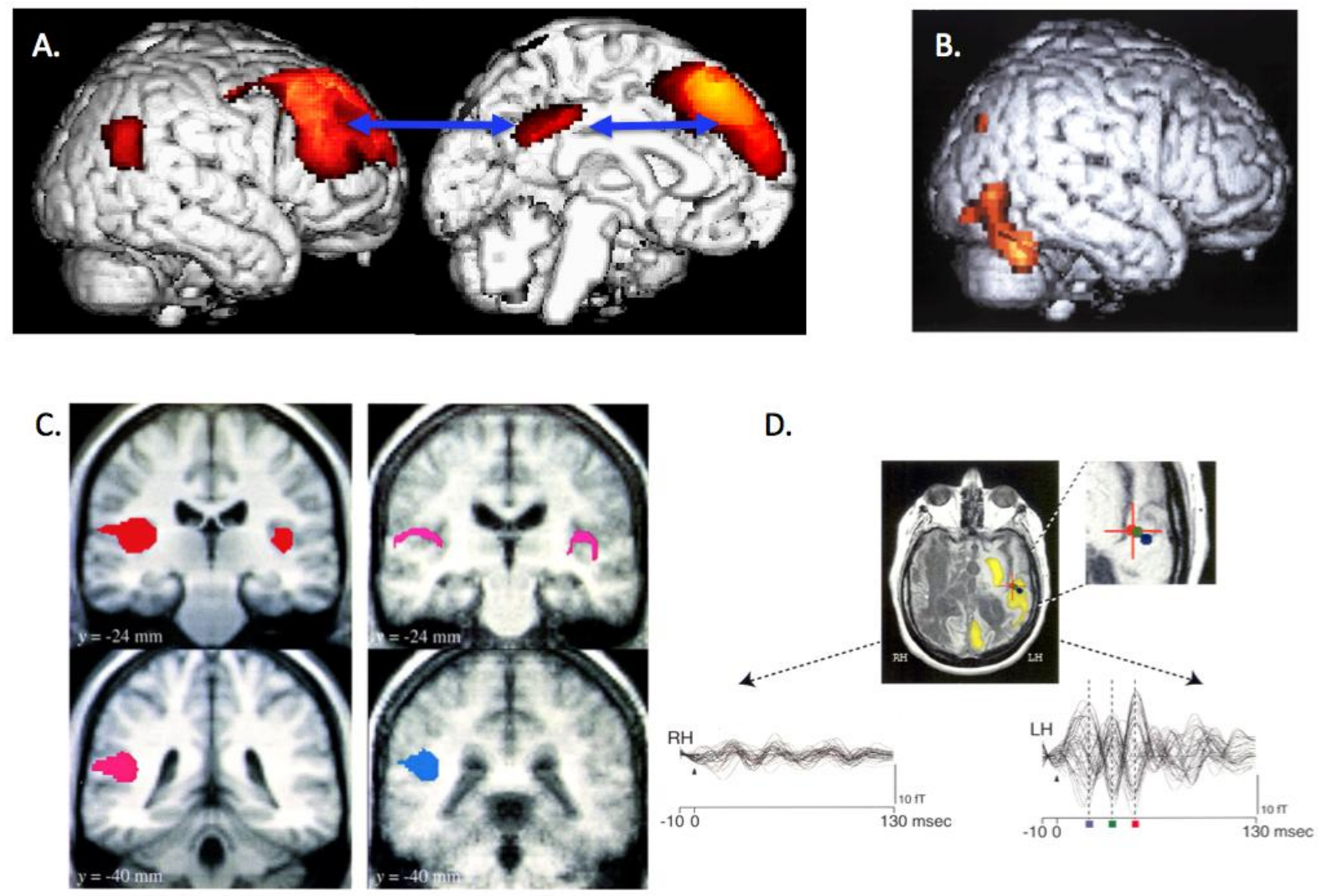

Figure 2. Loss of functional connectivity and modularity in the vegetative state.

A. Effective connectivity impairment in fronto-parietal consciousness network measured at rest (Laureys et al., 1999a).; B. Residual parahippocampal face area activation (Menon et al., 1998a) ; C. Residual low-level auditory activation disconnected from fronto-parietal network (Laureys et al., 2000a) ; D. Residual disconnected language network activation (Schiff et al., 1999). 


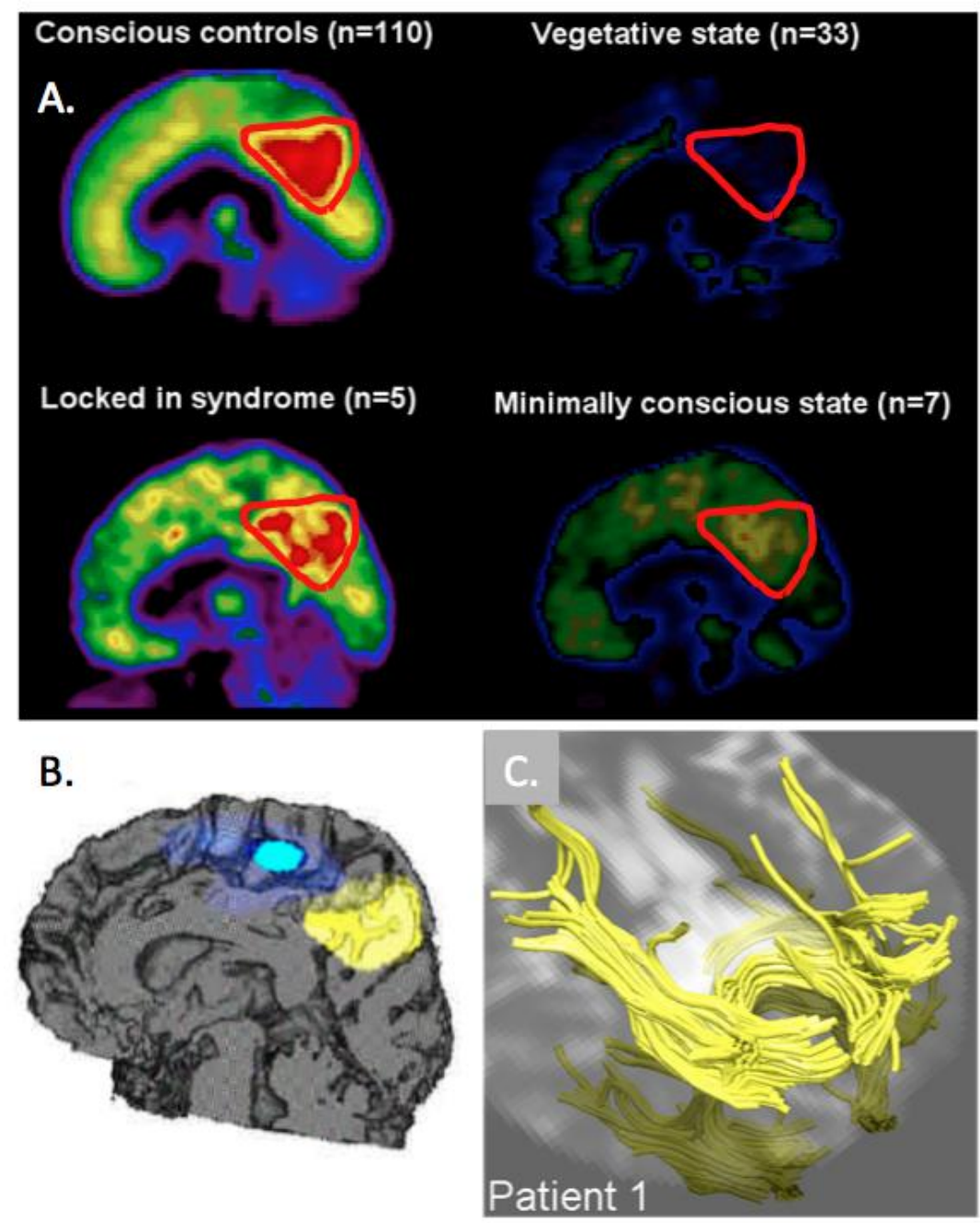

Figure 3. Role of posterior medial complex in process of recovery of consciousness.

A. Precuneus and adjacent posterior cingulate cortex (red triangle) is most active in conscious waking, most impaired in vegetative, preserved in locked-in and minimally active in minimally conscious states (Laureys et al., 2004a); B. Recovery of from VS is paralleled by recovery of metabolism in this area (in yellow) shown by FDG-PET (Laureys et al., 1999b); C. Late recovery of communication following chronic MCS is paralleled by possible axonal regrowth in this area shown by diffusion tensor MRI (Voss et al., 2006). 
A.
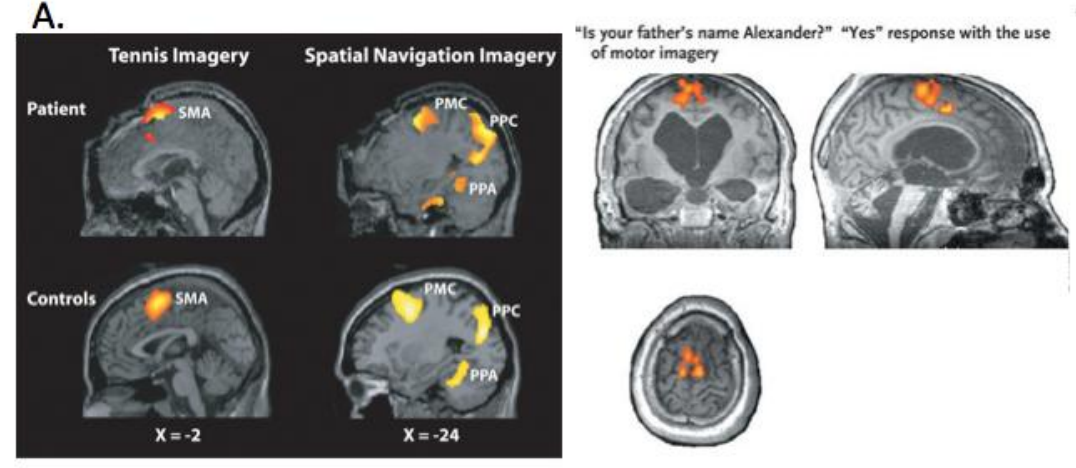

"Is your father's name Thomas?" "No" response with the use

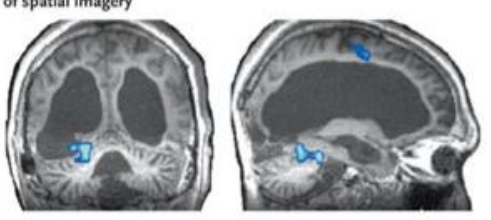

B.
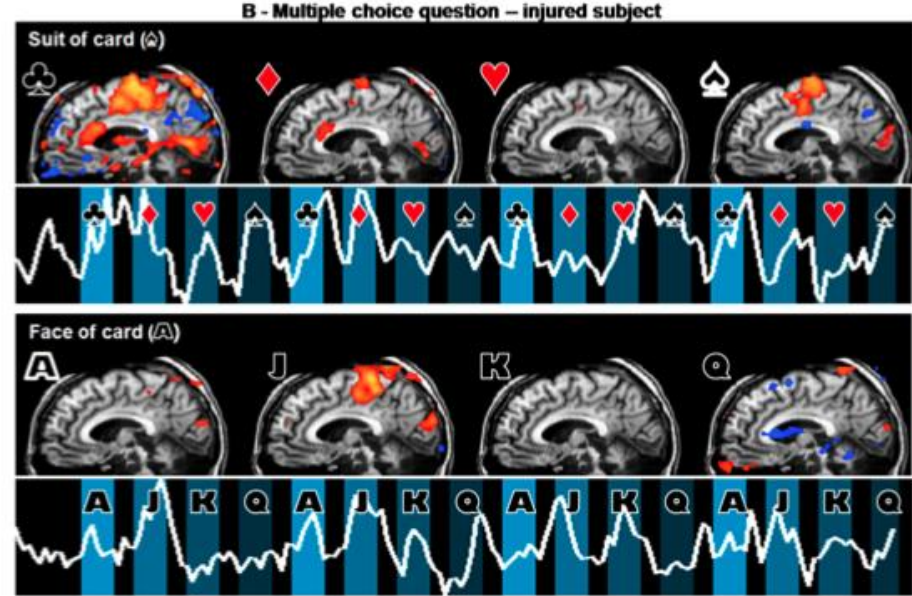

Figure 4. Assessment of command following and communication using functional neuroimaging.

Mental imagery tasks showing signs of consciousness (Owen et al., 2006) and communication (A. Monti et al., 2010b) (B. Bardin et al., 2011a) in severely brain damaged patients. 
A.

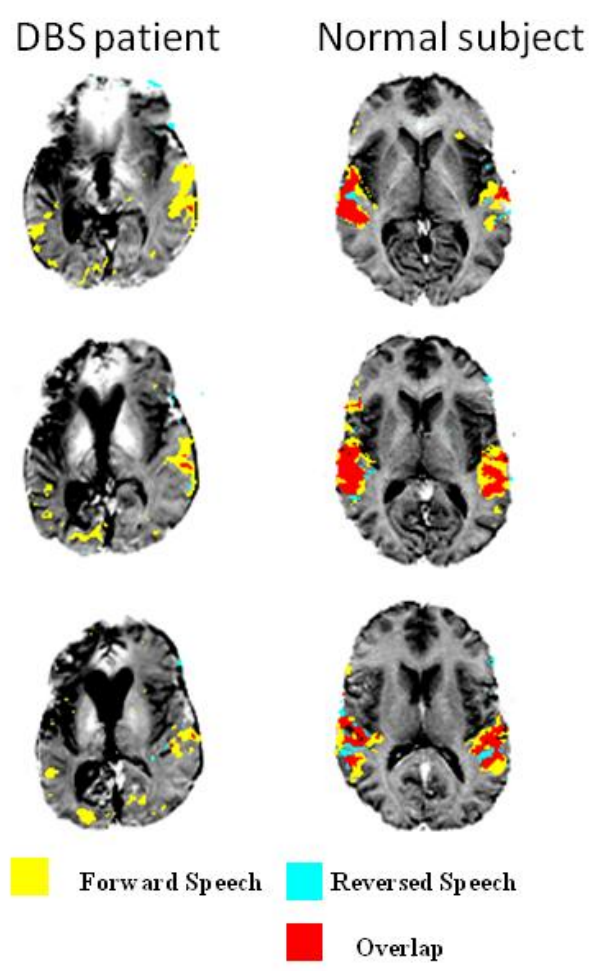

B.

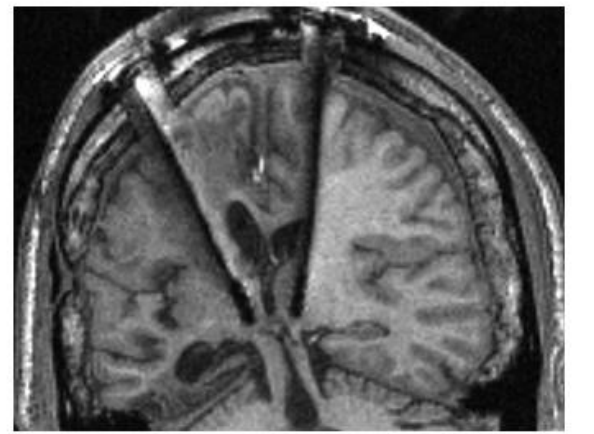

L

C.

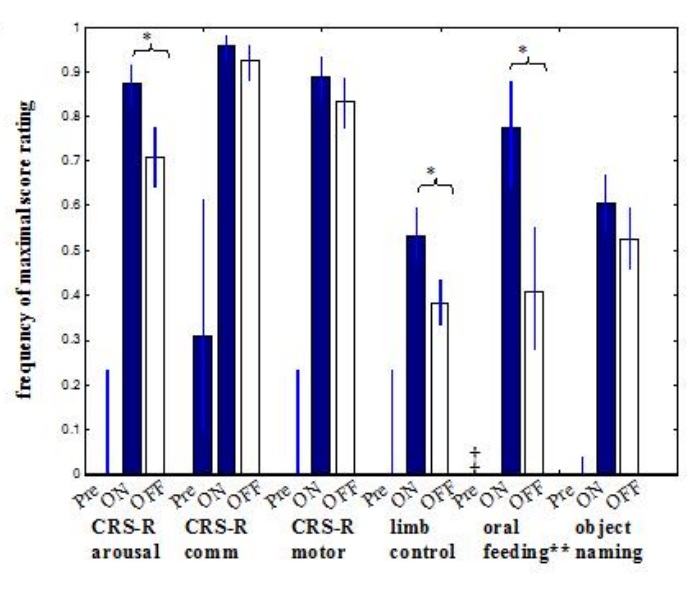

Figure 5. Proof of concept that central thalamic deep brain stimulation can facilitate recovery of behavioral responsiveness in the chronic minimally conscious state.

A. Residual activation of language areas in post-traumatic MCS (Schiff et al., 2002); B.

Bilateral thalamic stimulation in this selected patient improved clinical status (Schiff et al., 2007). 
A.

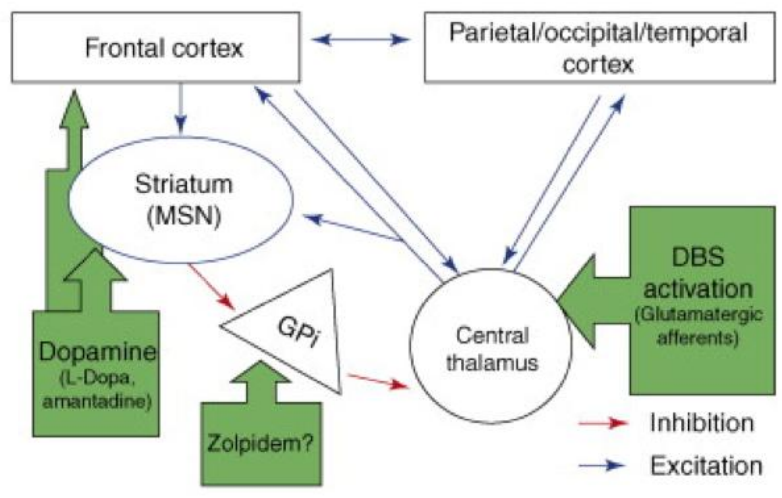

B.
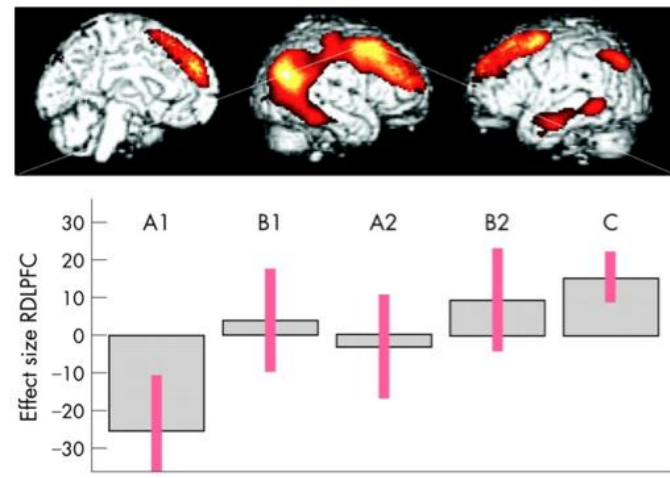

C.
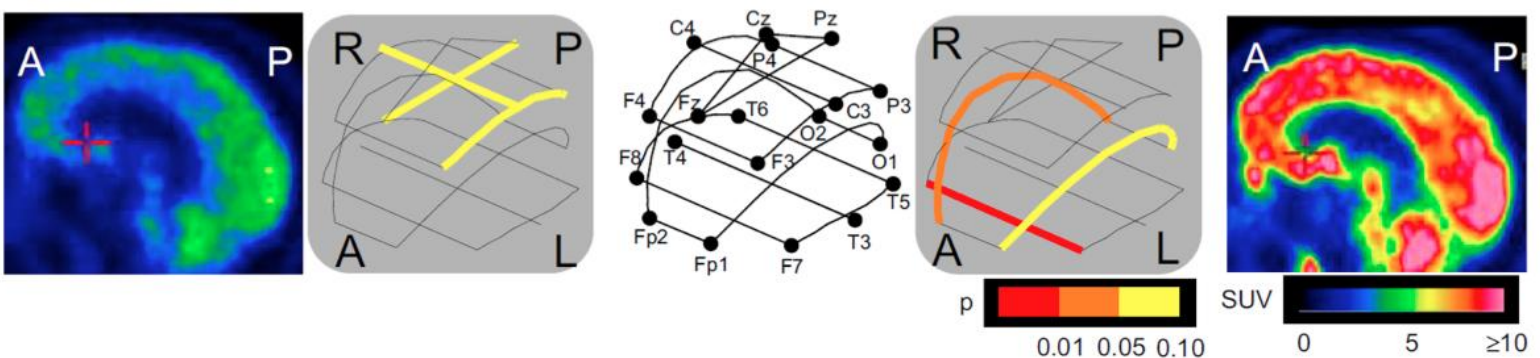

Figure 6. Linking models of spontaneous and induced recovery of consciousness: the

possible interactions of the anterior forebrain mesocircuit and posterior medial complex.

A. Mesocircuit hypothesis based on amantadine, zolpidem and DBS-induced recovery (Schiff, 2010); B. Amantadine-induced activation of frontoparietal network (Schnakers et al., 2008a); C. Restoration of fluctuations in coherence in a single zolpidem responsive patient (see Drover et al., 2010; Williams et al., 2009). 
Table 1. Functional neuroimaging data of the past 25 years measuring brain function in "resting state" conditions using (1) fluorodeoxyglucose positron emission tomography (FDG-PET) and (2) functional magnetic resonance imaging (fMRI) in chronic disorders of consciousness.

\begin{tabular}{|c|c|c|c|c|c|}
\hline Study & $\mathbf{N}^{\circ}$ & Diagnosis & Etiology & Duration & Main findings \\
\hline \multicolumn{6}{|l|}{ 1. FDG-PET } \\
\hline (Levy et al., 1987) & 7 & VS & TBI/NTBI & $1-72 \mathrm{~m}$ & $60 \%(53-67 \%)$ decrease in metabolism \\
\hline (De Volder et al., 1990) & 7 & VS & NTBI & $1-4 m$ & $53 \%(43-65 \%)$ decrease in metabolism \\
\hline (Tommasino et al., 1995) & 10 & VS & TBI/NTBI & $2-24 m$ & $56 \%$ decrease in metabolism \\
\hline (Plum et al., 1998) & 3 & VS & TBI/NTBI & & $50 \%$ decrease in metabolism with significant regional variations \\
\hline (Laureys et al., 1999a) & 4 & VS & TBI/ NTBI & $<1 \mathrm{~m}-60 \mathrm{~m}$ & FP hypometabolism \& disconnections \\
\hline (Laureys et al., 1999b) & 1 & VS & NTBI & $1 \mathrm{~m}$ & $38 \%$ decrease in metabolism; recovery of consciousness $=$ FP recovery \\
\hline (Rudolf et al., 1999) & 24 & VS & NTBI & $<1 \mathrm{~m}-6 \mathrm{~m}$ & $25 \%$ decrease in metabolism $(17 \%<3 \mathrm{~m}$ and $33 \%>3 \mathrm{~m})$ \\
\hline (Schiff and Plum, 1999) & 1 & VS & NTBI & $240 \mathrm{~m}$ & $50 \%$ decrease in metabolism with significant regional variations \\
\hline (Laureys et al., 2000b) & 1 & VS & NTBI & $4 \mathrm{~m}$ & recovery of consciousness $=$ thalamocortical reconnections \\
\hline (Rudolf et al., 2000) & 9 & VS & NTBI & $<1 \mathrm{~m}$ & decrease in benzodiazepine receptor density \\
\hline (Laureys et al., 2002a) & 30 & VS & TBI/ NTBI & $1-5 \mathrm{~m}$ & $56 \%(37-72 \%)$ decrease in metabolism \\
\hline (Schiff et al., 2002) & 5 & VS & TBI/NTBI & $6 m-240 m$ & $50 \%(31-87 \%)$ decrease in metabolism with regional variations \\
\hline (Beuthien-Baumann et al., 2003) & 16 & VS & TBI & $2-12 \mathrm{~m}$ & $58 \%$ decrease in metabolism; FP hypometabolism \\
\hline (Tengvar et al., 2004) & 1 & MCS & NTBI & $6 \mathrm{~m}$ & 47-65\% FP hypometabolism \\
\hline (Juengling et al., 2005) & 5 & VS & NTBI & $1-48 m$ & FP and thalamus hypometabolism \\
\hline (Nakayama et al., 2006) & 30 & $17 \mathrm{VS}$ & TBI & $6-60 m$ & FP and thalamus hypometabolism in VS, less impaired in MCS \\
\hline & & $13 \mathrm{MCS}$ & & & less impaired in MCS \\
\hline
\end{tabular}




\begin{tabular}{|c|c|c|c|c|c|}
\hline (Silva et al., 2010) & 10 & VS & TBI/ NTBI & $2-24 m$ & FP hypometabolism \\
\hline (Lull et al., 2010) & 17 & VS \& MCS & TBI & $12 \mathrm{~m}$ & thalamus hypometabolism \\
\hline (Bruno et al., 2010b) & 10 & VS & NTBI & $3 \mathrm{~m}$ & FP hypometabolism ( VS without fixation = "MCS" with fixation) \\
\hline \multicolumn{6}{|l|}{ 2. $f M R I$} \\
\hline (Boly et al., 2009) & 1 & VS & NTBI & $36 \mathrm{~m}$ & FP disconnections \\
\hline (Cauda et al., 2009) & 3 & VS & TBI/NTBI & $20 \mathrm{~m}$ & FP disconnections \\
\hline \multirow[t]{2}{*}{ (Vanhaudenhuyse et al., 2010) } & 13 & & TBI/NTBI & $<1-60 m$ & FP disconnections correlate with consciousness level \\
\hline & & $4 \mathrm{MCS}$ & & & \\
\hline
\end{tabular}

Note. $\mathrm{N}=$ Number of patients; VS = vegetative state; $\mathrm{MCS}$ = minimally conscious state; FP= frontoparietal associative network; TBI=traumatic brain injury; NTBI=non traumatic brain injury; $\mathrm{m}=$ months 
Table 2. Functional neuroimaging studies measuring brain activation to "passive" sensory stimulation using (1) $\mathrm{H}_{2}{ }^{15} \mathrm{O}$ PET (2) MEG and (3) fMRI in chronic disorders of consciousness.

\begin{tabular}{|c|c|c|c|c|c|c|}
\hline Study & $\mathbf{N}^{\circ}$ & Diagnosis & Etiology & Duration & Passive stimulation & Main findings \\
\hline \multicolumn{7}{|l|}{ 1. $\mathrm{H}_{2}^{15} \mathrm{O}$-PET } \\
\hline (de Jong et al., 1997) & 1 & VS & TBI & $2 \mathrm{~m}$ & auditory (familiar voice) & High level activation \\
\hline (Menon et al., 1998a) & 1 & vS & NTBI & $3 \mathrm{~m}$ & visual (familiar face) & Low level activation \\
\hline (Laureys et al., 2000a) & 5 & vS & TBI/NTBI & $3-38 d$ & auditory (click) & Low level disconnected \\
\hline (Laureys et al., 2002b) & 15 & VS & TBI/NTBI & $1 \mathrm{~m}$ & pain (electrical stimulation) & Low level disconnected \\
\hline \multirow[t]{2}{*}{ (Owen et al., 2002) } & 3 & $1 \mathrm{VS}$ & TBI/NTBI & $4 \mathrm{~m}$ & visual (familiar face), auditory (noise, words) & Low level activation \\
\hline & & $2 \mathrm{VS}$ & & & & High level activation \\
\hline (Kassubek et al., 2003) & 7 & VS & NTBI & $3-48 \mathrm{~m}$ & pain (electrical stimulation) & High level activation \\
\hline \multirow[t]{2}{*}{ (Boly et al., 2004) } & 20 & $15 \mathrm{VS}$ & TBI/NTBI & $1-4 m$ & auditory (click) & Low level disconnected \\
\hline & & $5 \mathrm{MCS}$ & & & & High level connected \\
\hline (Laureys et al., 2004b) & 1 & MCS & NTBI & $6 \mathrm{~m}$ & auditory (noise, cries, own name) & High level activation \\
\hline (Owen et al., 2005) & 1 & VS & NTBI & $4 \mathrm{~m}$ & auditory (speech) & High level activation \\
\hline (Giacino et al., 2006) & 5 & VS & TBI/NTBI & $1-3 m$ & visual (flash) & Low level activation \\
\hline \multirow[t]{2}{*}{ (Boly et al., 2008a) } & 15 & VS & & $1-4 \mathrm{~m}$ & pain (electrical stimulation) & Low level disconnected \\
\hline & 5 & MCS & & & & High level connected \\
\hline (Silva et al., 2010) & 10 & VS & TBI/NTBI & $2-22 m$ & tactile & Low level activation \\
\hline \multicolumn{7}{|l|}{ 2. $M E G$} \\
\hline (Schiff et al., 2002) & 5 & $5 \mathrm{VS}$ & TBI/NTBI & $6-240 \mathrm{~m}$ & auditory (click)/tactile & Low level activation \\
\hline
\end{tabular}




\section{3. $f M R I$}

(Bekinschtein et al., 2004)

TBI

$5 \mathrm{~m}$

auditory (familiar voice)

High level activation

(Bekinschtein et al., 2005)

(Schiff et al., 2005)

TBI

$2 \mathrm{~m}$

auditory (words)

TBI/NTBI

auditory (speech), tactile

Low level activation

(Owen et al., 2006)

(Staffen et al., 2006)

(Di et al., 2007)

TBI

auditory (speech, ambiguity), visual

NTBI

$6 \mathrm{~m}$

auditory (own name)

TBI/NTBI

$2-48 m$

auditory (familiar voice own name )

$2 \mathrm{VS}$

4 MCS

(Coleman et al., 2007)

12

$4 \mathrm{VS}$

$3 \mathrm{VS}$

5 MCS

(Fernandez-Espejo et al., 2008)

7

2 VS

$1 \mathrm{VS}$

$4 \mathrm{MCS}$

(Rousseau et al., 2008)

VS

NTBI

TBI/NTBI

$2-120 m$

auditory (forward/backward speech,

$46 \quad 20 \mathrm{VS}$

$7 \mathrm{VS}$

ambiguity)

auditory (forward/backward speech,

ambiguity)

level activation

High level activation

Low/high level activation

Low level activation

High level activation

Low/high level activation

Low level activation

Low level activation

High level activation

Low/high level activation 


\begin{tabular}{|c|c|c|c|c|c|c|}
\hline (Zhu et al., 2009) & 9 & MCS & TBI/NTBI & $1-2 m$ & visual (emotional picture) & High level activation \\
\hline \multirow[t]{2}{*}{ (Qin et al., 2010) } & 11 & $7 \mathrm{VS}$ & TBI/NTBI & $2-48 m$ & auditory (familiar voice own name) & Low level activation \\
\hline & & $4 \mathrm{MCS}$ & & & & High level activation \\
\hline \multirow[t]{2}{*}{ (Fernandez-Espejo et al., 2010b) } & 1 & VS & TBI & $1 \mathrm{~m}$ & auditory (speech forward/backward) & High level activation \\
\hline & & & & $<2 \mathrm{~m},>$ & & \\
\hline \multirow[t]{2}{*}{ (Heelmann et al., 2010) } & 6 & $6 \mathrm{VS}$ & TBI & $\mathrm{m}$ & visual (flash) & Low level activation \\
\hline & & $1 \mathrm{MCS}$ & & $14 \mathrm{~m}$ & & High level activation \\
\hline
\end{tabular}

Note. $\mathrm{N}=$ Number of patients; VS = vegetative state/unresponsive wakefulness syndrome; MCS = minimally conscious state; FP= frontoparietal associative network ; TBI=traumatic brain injury; NTBI=non traumatic brain injury; $\mathrm{m}=$ months. 
Table 3. Functional neuroimaging studies using “active” tasks assessing (1) consciousness or (2) communication using fMRI, evoked potentials or electromyography in chronic disorders of consciousness.

\begin{tabular}{|c|c|c|c|c|c|c|c|}
\hline Study & Technique & $\mathbf{N}^{\circ}$ & Diagnosis & Etiology & Duration & Active task & Main findings \\
\hline \multicolumn{8}{|c|}{ 1. Assessing consciousness } \\
\hline Owen et al. 2006 & fMRI & 1 & VS & TBI & $5 \mathrm{~m}$ & $\begin{array}{l}\text { Motor and spatial } \\
\text { mental imagery }\end{array}$ & $\begin{array}{l}\text { Activation of supplementary motor area for motor task. Activation of } \\
\text { parahippocampal gyrus, posterior parietal and premotor cortex for } \\
\text { spatial task }\end{array}$ \\
\hline $\begin{array}{l}\text { Schnakers et al. } \\
2008\end{array}$ & ERPs & $\begin{array}{c}22 / 29 \\
\text { included }\end{array}$ & $\begin{array}{l}8 \mathrm{VS} \\
14 \mathrm{MCS}\end{array}$ & $\begin{array}{l}10 \mathrm{TBI} \\
12 \mathrm{NTBI}\end{array}$ & $12 \mathrm{~d}-24 \mathrm{y}$ & $\begin{array}{l}\text { Silently names } \\
\text { counting }\end{array}$ & Increased P3 amplitude in 9MCS when counting target name \\
\hline $\begin{array}{l}\text { Bekinschtein et } \\
\text { al. } 2008\end{array}$ & EMG & 10 & $\begin{array}{l}8 \mathrm{VS} \\
2 \mathrm{MCS}\end{array}$ & $\begin{array}{l}6 \mathrm{TBI} \\
4 \mathrm{NTBI}\end{array}$ & - & Motor & Increased EMG activity when asked to move in 1VS and 2MCS. \\
\hline $\begin{array}{l}\text { Schnakers et al. } \\
2009\end{array}$ & ERPs & 1 & Total LIS & NTBI & $25 \mathrm{~d}$ & $\begin{array}{l}\text { Silently names } \\
\text { counting }\end{array}$ & Increased P3 amplitude when counting target name \\
\hline $\begin{array}{l}\text { Bekinschtein et } \\
\text { al. } 2009\end{array}$ & ERPs & 8 & $\begin{array}{l}4 \mathrm{VS} \\
3 \mathrm{MCS} \\
1 \mathrm{LIS}\end{array}$ & $\begin{array}{l}3 \mathrm{TBI} \\
5 \mathrm{NTBI}\end{array}$ & $50 \mathrm{~d}$ & $\begin{array}{l}\text { Global/local } \\
\text { auditory } \\
\text { irregularity } \\
\text { detection }\end{array}$ & Global regularities violation effect in 2 MCS and 1LIS \\
\hline Monti et al. 2010 & fMRI & 54 & $\begin{array}{l}23 \mathrm{VS} \\
31 \mathrm{MCS}\end{array}$ & $\begin{array}{l}32 \mathrm{TBI} \\
22 \mathrm{NTBI}\end{array}$ & $22 \mathrm{~m}$ & $\begin{array}{l}\text { Motor and spatial } \\
\text { mental imagery }\end{array}$ & $\begin{array}{l}\text { Activation of supplementary motor area for motor task in 4VS and } \\
\text { 1MCS. Activation of parahippocampal gyrus for spatial task in 3VS } \\
\text { and 1MCS }\end{array}$ \\
\hline $\begin{array}{l}\text { Rodriguez } \\
\text { Moreno et al. } \\
2010\end{array}$ & fMRI & $\begin{array}{c}10 / 17 \\
\text { included }\end{array}$ & $\begin{array}{l}3 \text { VS 5MCS } \\
1 \mathrm{EMCS} \\
1 \text { LIS }\end{array}$ & $\begin{array}{l}5 \mathrm{TBI} \\
5 \mathrm{NTBI}\end{array}$ & $20 \mathrm{~m}$ & $\begin{array}{l}\text { Silently picture } \\
\text { naming }\end{array}$ & $\begin{array}{l}\text { Activation of left superior temporal, inferior frontal and pre- } \\
\text { supplementary motor area in 1VS, 2MCS, 1LIS, 1EMCS }\end{array}$ \\
\hline
\end{tabular}




\begin{tabular}{|c|c|c|c|c|c|c|c|}
\hline $\begin{array}{l}\text { Bekinschtein et } \\
\text { al. } 2011\end{array}$ & fMRI & $\begin{array}{c}5 / 43 \\
\text { included }\end{array}$ & VS & $\begin{array}{l}\text { 4TBI } \\
\text { 1TBI-anoxic }\end{array}$ & $10 \mathrm{~d}$ & Motor task & Activation of contralateral dorsal premotor cortex in $2 \mathrm{VS}$ \\
\hline Bardin et al. 2011 & fMRI & 6/7 included & $\begin{array}{l}5 \mathrm{MCS} \\
1 \mathrm{LIS}\end{array}$ & $\begin{array}{l}4 \mathrm{TBI} \\
2 \mathrm{NTBI}\end{array}$ & $6 \mathrm{~m}-3 \mathrm{y}$ & $\begin{array}{l}\text { Motor mental } \\
\text { imagery }\end{array}$ & Activation of supplementary motor area in $2 \mathrm{MCS}$ and 1LIS \\
\hline \multicolumn{8}{|c|}{ 2. Assessing communication } \\
\hline Monti et al. 2010 & fMRI & $\begin{array}{c}1 / 54 \\
\text { included }\end{array}$ & VS & TBI & $1 \mathrm{~m}-25 \mathrm{y}$ & $\begin{array}{l}\text { Yes (motor mental } \\
\text { imagery) -or-no } \\
\text { (spatial mental } \\
\text { imagery) } \\
\text { autobiographical } \\
\text { questions. }\end{array}$ & Correct responses in expected brain regions in 5 out of 6 questions \\
\hline Bardin et al. 2011 & fMRI & 4/7 included & $\begin{array}{l}3 \mathrm{MCS} \\
1 \mathrm{LIS}\end{array}$ & $\begin{array}{l}2 \mathrm{TBI} \\
2 \mathrm{NTBI}\end{array}$ & $6 \mathrm{~m}-3 \mathrm{y}$ & $\begin{array}{l}\text { Binary and } \\
\text { multiple choices } \\
\text { tasks }\end{array}$ & Incorrect responses in expected brain regions in $1 \mathrm{MCS}$ \\
\hline
\end{tabular}

fMRI: functional Magnetic Resonance Imaging; ERPs: Event Related Potentials; EMG: Electromyography; VS: Vegetative State; MCS: Minimally Conscious State; EMCS: Emerged from Minimally Conscious State ;

LIS: Locked-In Syndrome; NA: Not Applicable; d: days; m: months, y: years; TBI: traumatic brain injury; NTBI: non-traumatic brain injury. 


\section{References}

Baars, B., Ramsoy, T., Laureys, S., 2003. Brain, conscious experience and the observing self. Trends Neurosci 26, 671-675.

Babiloni, C., Sara, M., Vecchio, F., Pistoia, F., Sebastiano, F., Onorati, P., Albertini, G., Pasqualetti, P., Cibelli, G., Buffo, P., Rossini, P.M., 2009. Cortical sources of resting-state alpha rhythms are abnormal in persistent vegetative state patients. Clin Neurophysiol $120,719-729$.

Bagnato, S., Boccagni, C., Prestandrea, C., Sant'Angelo, A., Castiglione, A., Galardi, G., 2010. Prognostic value of standard EEG in traumatic and non-traumatic disorders of consciousness following coma. Clin Neurophysiol 121, 274-280.

Bardin, J.C., Fins, J.J., Katz, D.I., Hersh, J., Heier, L.A., Tabelow, K., Dyke, J.P., Ballon, D.J., Schiff, N.D., Voss, H.U., 2011a. Dissociations between behavioural and functional magnetic resonance imaging-based evaluations of cognitive function after brain injury. Brain 134, 769-782.

Bardin, J.C., Schiff, N.D., Voss, H.U., 2011b. Pattern Classification of Volitional fMRI Responses in Severely Brain-Injured Subjects. Arch Neurol, in press.

Bekinschtein, T., Leiguarda, R., Armony, J., Owen, A., Carpintiero, S., Niklison, J., Olmos, L., Sigman, L., Manes, F., 2004. Emotion processing in the minimally conscious state. J Neurol Neurosurg Psychiatry 75, 788.

Bekinschtein, T., Tiberti, C., Niklison, J., Tamashiro, M., Carpintiero, S., Villarreal, M., Forcato, C., Leiguarda, R., Manes, F., 2005. Assessing level of consciousness and cognitive changes from vegetative state to full recovery. Neuropsychological Rehabilitation 15, 307-322. 
Bekinschtein, T.A., Coleman, M.R., Niklison, J., 3rd, Pickard, J.D., Manes, F.F., 2008. Can electromyography objectively detect voluntary movement in disorders of consciousness? J Neurol Neurosurg Psychiatry 79, 826-828.

Bekinschtein, T.A., Dehaene, S., Rohaut, B., Tadel, F., Cohen, L., Naccache, L., 2009a. Neural signature of the conscious processing of auditory regularities. Proc Natl Acad Sci U S A 106, 1672-1677.

Bekinschtein, T.A., Manes, F.F., Villarreal, M., Owen, A.M., Della-Maggiore, V., 2011. Functional imaging reveals movement preparatory activity in the vegetative state. Front Hum Neurosci 5, 5.

Bekinschtein, T.A., Shalom, D.E., Forcato, C., Herrera, M., Coleman, M.R., Manes, F.F., Sigman, M., 2009b. Classical conditioning in the vegetative and minimally conscious state. Nat Neurosci 12, 1343-1349.

Beuthien-Baumann, B., Handrick, W., Schmidt, T., Burchert, W., Oehme, L., Kropp, J., Schackert, G., Pinkert, J., Franke, W.G., 2003. Persistent vegetative state: evaluation of brain metabolism and brain perfusion with PET and SPECT. Nucl Med Commun 24, 643649.

Boly, M., Coleman, M.R., Davis, M.H., Hampshire, A., Bor, D., Moonen, G., Maquet, P.A., Pickard, J.D., Laureys, S., Owen, A.M., 2007. When thoughts become action: an fMRI paradigm to study volitional brain activity in non-communicative brain injured patients. Neuroimage 36, 979-992.

Boly, M., Faymonville, M.E., Peigneux, P., Lambermont, B., Damas, P., Del Fiore, G., Degueldre, C., Franck, G., Luxen, A., Lamy, M., Moonen, G., Maquet, P., Laureys, S., 2004. Auditory processing in severely brain injured patients: differences between the minimally conscious state and the persistent vegetative state. Arch Neurol 61, 233-238. 
Boly, M., Faymonville, M.E., Schnakers, C., Peigneux, P., Lambermont, B., Phillips, C., Lancellotti, P., Luxen, A., Lamy, M., Moonen, G., Maquet, P., Laureys, S., 2008a. Perception of pain in the minimally conscious state with PET activation: an observational study. Lancet Neurol 7, 1013-1020.

Boly, M., Garrido, M.I., Gosseries, O., Bruno, M.A., Boveroux, P., Schnakers, C., Massimini, M., Litvak, V., Laureys, S., Friston, K., 2011. Preserved feedforward but impaired topdown processes in the vegetative state. Science 332, 858-862.

Boly, M., Phillips, C., Balteau, E., Schnakers, C., Degueldre, C., Moonen, G., Luxen, A., Peigneux, P., Faymonville, M.E., Maquet, P., Laureys, S., 2008b. Consciousness and cerebral baseline activity fluctuations. Hum Brain Mapp 29, 868-874.

Boly, M., Tshibanda, L., Vanhaudenhuyse, A., Noirhomme, Q., Schnakers, C., Ledoux, D., Boveroux, P., Garweg, C., Lambermont, B., Phillips, C., Luxen, A., Moonen, G., Bassetti, C., Maquet, P., Laureys, S., 2009. Functional connectivity in the default network during resting state is preserved in a vegetative but not in a brain dead patient. Hum Brain Mapp, in press

Boveroux, P., Bonhomme, V., Boly, M., Vanhaudenhuyse, A., Maquet, P., Laureys, S., 2008. Brain function in physiologically, pharmacologically, and pathologically altered states of consciousness. Int Anesthesiol Clin 46, 131-146.

Boveroux, P., Vanhaudenhuyse, A., Bruno, M.A., Noirhomme, Q., Lauwick, S., Luxen, A., Degueldre, C., Plenevaux, A., Schnakers, C., Phillips, C., Brichant, J.F., Bonhomme, V., Maquet, P., Greicius, M.D., Laureys, S., Boly, M., 2010. Breakdown of within- and between-network resting state functional magnetic resonance imaging connectivity during propofol-induced loss of consciousness. Anesthesiology 113, 1038-1053. 
Brefel-Courbon, C., Payoux, P., Ory, F., Sommet, A., Slaoui, T., Raboyeau, G., Lemesle, B., Puel, M., Montastruc, J.L., Demonet, J.F., Cardebat, D., 2007. Clinical and imaging evidence of zolpidem effect in hypoxic encephalopathy. Ann Neurol 62, 102-105.

Brown, E.N., Lydic, R., Schiff, N.D., General anesthesia, sleep, and coma. N Engl J Med 363, 2638-2650.

Bruno, M., Schnakers, C., Damas, F., Pellas, F., Lutte, I., Bernheim, J., Majerus, S., Moonen, G., Goldman, S., Laureys, S., 2009a. Locked-in syndrome in children: report of five cases and review of the literature. Pediatr Neurol 41, 237-246.

Bruno, M.-A., Fernández-Espejo, D., Lehembre, R., Tshibanda, L., Vanhaudenhuyse, A., Gosseries, O., Lommers, E., Noirhomme, Q., Boly, M., Napolitani, M., Owen, A.M., Laureys, S., Soddu, A., 2010a. Multi-modal imaging in left hemisphere damaged patients with disorders of consciousness. Prog Brain Res in press.

Bruno, M.-A., Ledoux, D., Lambermont, B., Damas, F., Schnakers, C., Vanhaudenhuyse, A., Gosseries, O., Laureys, S., 2011a. Comparison of the Full Outline of UnResponsiveness and Glasgow Liege Scale/Glasgow Coma Scale in an intensive care unit population. Neurocritical Care, In press.

Bruno, M.-A., Vanhaudenhuyse, A., Thibaut, A., Moonen, G., Laureys, S., 2011b. From unresponsive wakefulness to minimally conscious PLUS and functional locked-in syndromes: Recent advances in our understanding of disorders of consciousness. Journal of Neurology, in press.

Bruno, M.A., Schnakers, C., Damas, F., Pellas, F., Lutte, I., Bernheim, J., Majerus, S., Moonen, G., Goldman, S., Laureys, S., 2009b. Locked-in syndrome in children: report of five cases and review of the literature. Pediatr Neurol 41, 237-246. 
Bruno, M.A., Vanhaudenhuyse, A., Schnakers, C., Boly, M., Gosseries, O., Demertzi, A., Majerus, S., Moonen, G., Hustinx, R., Laureys, S., 2010b. Visual fixation in the vegetative state: an observational case series PET study. BMC Neurol 10, 35.

Buckwalter, J.A., Parvizi, J., Morecraft, R.J., van Hoesen, G.W., 2008. Thalamic projections to the posteromedial cortex in the macaque. J Comp Neurol 507, 1709-1733.

Cauda, F., Micon, B., Sacco, K., Duca, S., D'Agata, F., Geminiani, G., Canavero, S., 2009.

Disrupted intrinsic functional connectivity in the vegetative state. J Neurol Neurosurg Psychiatry 80, 429-431.

Cavinato, M., Freo, U., Ori, C., Zorzi, M., Tonin, P., Piccione, F., Merico, A., 2009. Post-acute P300 predicts recovery of consciousness from traumatic vegetative state. Brain Inj 23, 973-980.

Clauss, R., Nel, W., 2006. Drug induced arousal from the permanent vegetative state. NeuroRehabilitation 21, 23-28.

Coleman, M., Davis, M., Rodd, J., Robson, T., Ali, A., Owen, A., Pickard, J., 2009. Towards the routine use of brain imaging to aid the clinical diagnosis of disorders of consciousness. Brain 132, 2541-2552.

Coleman, M.R., Rodd, J.M., Davis, M.H., Johnsrude, I.S., Menon, D.K., Pickard, J.D., Owen, A.M., 2007. Do vegetative patients retain aspects of language comprehension? Evidence from fMRI. Brain 130, 2494-2507.

Cologan, V., Schabus, M., Ledoux, D., Moonen, G., Maquet, P., Laureys, S., 2010. Sleep in disorders of consciousness. Sleep Med Rev 14, 97-105.

de Jong, B., Willemsen, A.T., Paans, A.M., 1997. Regional cerebral blood flow changes related to affective speech presentation in persistent vegetative state. Clin. Neurol. Neurosurg. 99, 213-216. 
De Volder, A.G., Goffinet, A.M., Bol, A., Michel, C., de, B.T., Laterre, C., 1990. Brain glucose metabolism in postanoxic syndrome. Positron emission tomographic study. Arch. Neurol. 47, 197-204.

Dehaene, S., 2000. The Cognitive Neuroscience of Consciousness. MIT Press, Cambridge, MA.

Di, H., Boly, M., Weng, X., Ledoux, D., Laureys, S., 2008. Neuroimaging activation studies in the vegetative state: predictors of recovery? Clinical Medicine, in press.

Di, H.B., Yu, S.M., Weng, X.C., Laureys, S., Yu, D., Li, J.Q., Qin, P.M., Zhu, Y.H., Zhang, S.Z., Chen, Y.Z., 2007. Cerebral response to patient's own name in the vegetative and minimally conscious states. Neurology 68, 895-899.

Drover, J.D., Schiff, N.D., Victor, J.D., 2010. Dynamics of coupled thalamocortical modules. J Comput Neurosci 28, 605-616.

Fellinger, R., Klimesch, W., Schnakers, C., Perrin, F., Freunberger, R., Gruber, W., Laureys, S., Schabus, M., 2011. Cognitive processes in disorders of consciousness as revealed by EEG time-frequency analyses. Clin Neurophysiol.

Fernandez-Espejo, D., Bekinschtein, T., Monti, M.M., Pickard, J.D., Junque, C., Coleman, M.R., Owen, A.M., 2010a. Diffusion weighted imaging distinguishes the vegetative state from the minimally conscious state. Neuroimage 1, 103-112.

Fernandez-Espejo, D., Junque, C., Cruse, D., Bernabeu, M., Roig-Rovira, T., Fábregas, N., Rivas, E., Mercader, J., 2010b. Combination of diffusion tensor and functional magnetic resonance imaging during recovery from the vegetative state. BMC Neurol. 10, 77. Fernandez-Espejo, D., Junque, C., Vendrell, P., Bernabeu, M., Roig, T., Bargallo, N., Mercader, J.M., 2008. Cerebral response to speech in vegetative and minimally conscious states after traumatic brain injury. Brain Inj 22, 882-890. 
Fins, J., Illes, J., Bernat, J., Hirsch, J., Laureys, S., Murphy, E., 2008a. Neuroimaging and disorders of consciousness: envisioning an ethical research agenda. Am J Bioeth. 8, 3-12. Fins, J.J., 2009a. Being conscious of their burden: severe brain injury and the two cultures challenge. Ann N Y Acad Sci 1157, 131-147.

Fins, J.J., 2009b. The ethics of measuring and modulating consciousness: the imperative of minding time. Prog Brain Res 177, 371-382.

Fins, J.J., Illes, J., Bernat, J.L., Hirsch, J., Laureys, S., Murphy, E., 2008b. Neuroimaging and disorders of consciousness: envisioning an ethical research agenda. Am J Bioeth 8, 3-12. Fins, J.J., Schiff, N.D., 2010. Conflicts of interest in deep brain stimulation research and the ethics of transparency. J Clin Ethics 21, 125-132.

Giacino, J.T., Ashwal, S., Childs, N., Cranford, R., Jennett, B., Katz, D.I., Kelly, J.P., Rosenberg, J.H., Whyte, J., Zafonte, R.D., Zasler, N.D., 2002. The minimally conscious state: Definition and diagnostic criteria. Neurology 58, 349-353.

Giacino, J.T., Hirsch, J., Schiff, N., Laureys, S., 2006. Functional neuroimaging applications for assessment and rehabilitation planning in patients with disorders of consciousness. Arch Phys Med Rehabil 87, 67-76.

Giacino, J.T., Kalmar, K., Whyte, J., 2004. The JFK Coma Recovery Scale-Revised: measurement characteristics and diagnostic utility. Arch Phys Med Rehabil 85, 2020 2029.

Giacino, J.T., Schnakers, C., Rodriguez-Moreno, D., Kalmar, K., Schiff, N., Hirsch, J., 2009. Behavioral assessment in patients with disorders of consciousness: gold standard or fool's gold? Prog Brain Res 177, 33-48.

Gold, L., Lauritzen, M., 2002. Neuronal deactivation explains decreased cerebellar blood flow in response to focal cerebral ischemia or suppressed neocortical function. Proc Natl Acad Sci U S A 99, 7699-7704. 
Goldfine, A.M., Victor, J.D., Conte, M.M., Bardin, J.C., Schiff, N.D., 2011. Determination of awareness in patients with severe brain injury using EEG power spectral analysis. Clin Neurophysiol.

Gosseries, O., Bruno, M.-A., vanhaudenhuyse, A., Laureys, S., Schnakers, C., 2009. Consciousness in the Locked-in Syndrome. In: Laureys, S., Tononi, G. (Eds.), The Neurology of Consciousness: Cognitive Neuroscience and Neuropathology. Elsevier, Oxford, pp. 191-203.

Heckers, S., Geula, C., Mesulam, M.M., 1992. Cholinergic innervation of the human thalamus: dual origin and differential nuclear distribution. J Comp Neurol 325, 68-82. Heelmann, V., Lippert-Grüner, M., Rommel, T., Wedekind, C., 2010. Abnormal functional MRI BOLD contrast in the vegetative state after severe traumatic brain injury. Int J Rehabil Res. 33, 151-157.

Hirsch, J., Kamal, A., Moreno, D., Petrovich, N., Giacino, J., Plum, F., Schiff, N., 2001. fMRI reveals intact cognitive systems for two minimally conscious patients. Society for Neuroscience, Abstracts 271, 1397.

Jennett, B., 2005. Thirty years of the vegetative state: clinical, ethical and legal problems. Prog Brain Res 150, 537-543.

Juengling, F.D., Kassubek, J., Huppertz, H.J., Krause, T., Els, T., 2005. Separating functional and structural damage in persistent vegetative state using combined voxel-based analysis of 3-D MRI and FDG-PET. J Neurol Sci 228, 179-184.

Kassubek, J., Juengling, F.D., Els, T., Spreer, J., Herpers, M., Krause, T., Moser, E., Lucking, C.H., 2003. Activation of a residual cortical network during painful stimulation in longterm postanoxic vegetative state: a 150-H20 PET study. J Neurol Sci 212, 85-91. Katz, D.I., Alexander, M.P., Mandell, A.M., 1987. Dementia following strokes in the mesencephalon and diencephalon. Arch Neurol 44, 1127-1133. 
Kim, Y.W., Shin, J.C., An, Y.S., 2009. Effects of methylphenidate on cerebral glucose metabolism in patients with impaired consciousness after acquired brain injury. Clin Neuropharmacol 32, 335-339.

Kinney, H.C., Korein, J., Panigrahy, A., Dikkes, P., Goode, R., 1994. Neuropathological findings in the brain of Karen Ann Quinlan - the role of the thalamus in the persistent vegetative state. N Engl J Med 330, 1469-1475.

Kupers, R., Faymonville, M.E., Laureys, S., 2005. The cognitive modulation of pain : Hypnosis -and placebo-induced analgesia. In: Laureys, S. (Ed.), The boundaries of consciousness: neurobiology and neuropathology. Elsevier, Amsterdam, pp. 251-269. Landsness, E., Bruno, M.-A., Noirhomme, Q., Riedner, B., Gosseries, O., Schnakers, C., Massimini, M., Laureys, S., 2011. Electrophysiological correlates of behavioural changes in vigilance in vegetative state and minimally conscious state. Brain, in press.

Laureys, S., 2004. Functional neuroimaging in the vegetative state. NeuroRehabilitation $19,335-341$.

Laureys, S., 2005a. The neural correlate of (un)awareness: lessons from the vegetative state. Trends Cogn Sci 9, 556-559.

Laureys, S., 2005b. Science and society: death, unconsciousness and the brain. Nat Rev Neurosci 6, 899-909.

Laureys, S., Antoine, S., Boly, M., Elincx, S., Faymonville, M.E., Berre, J., Sadzot, B., Ferring, M., De Tiege, X., van Bogaert, P., Hansen, I., Damas, P., Mavroudakis, N., Lambermont, B., Del Fiore, G., Aerts, J., Degueldre, C., Phillips, C., Franck, G., Vincent, J.L., Lamy, M., Luxen, A., Moonen, G., Goldman, S., Maquet, P., 2002a. Brain function in the vegetative state. Acta Neurol Belg 102, 177-185.

Laureys, S., Boly, M., 2007. What is it like to be vegetative or minimally conscious? Curr Opin Neurol 20, 609-613. 
Laureys, S., Boly, M., 2008. The changing spectrum of coma. Nat Clin Pract Neurol 4, 544546.

Laureys, S., Boly, M., Maquet, P., 2006. Tracking the recovery of consciousness from coma. J Clin Invest 116, 1823-1825.

Laureys, S., Celesia, G.G., Cohadon, F., Lavrijsen, J., Leon-Carrion, J., Sannita, W.G., Sazbon, L., Schmutzhard, E., von Wild, K.R., Zeman, A., Dolce, G., 2010. Unresponsive wakefulness syndrome: a new name for the vegetative state or apallic syndrome. BMC Med 8, 68. Laureys, S., Faymonville, M.E., Degueldre, C., Fiore, G.D., Damas, P., Lambermont, B., Janssens, N., Aerts, J., Franck, G., Luxen, A., Moonen, G., Lamy, M., Maquet, P., 2000a. Auditory processing in the vegetative state. Brain 123, 1589-1601.

Laureys, S., Faymonville, M.E., Luxen, A., Lamy, M., Franck, G., Maquet, P., 2000b.

Restoration of thalamocortical connectivity after recovery from persistent vegetative state. Lancet 355, 1790-1791.

Laureys, S., Faymonville, M.E., Peigneux, P., Damas, P., Lambermont, B., Del Fiore, G., Degueldre, C., Aerts, J., Luxen, A., Franck, G., Lamy, M., Moonen, G., Maquet, P., 2002b. Cortical processing of noxious somatosensory stimuli in the persistent vegetative state. Neuroimage 17, 732-741.

Laureys, S., Goldman, S., Phillips, C., Van Bogaert, P., Aerts, J., Luxen, A., Franck, G., Maquet, P., 1999a. Impaired effective cortical connectivity in vegetative state. Neuroimage 9, 377-382.

Laureys, S., Lemaire, C., Maquet, P., Phillips, C., Franck, G., 1999b. Cerebral metabolism during vegetative state and after recovery to consciousness. J. Neurol. Neurosurg. Psychiatry 67, 121.

Laureys, S., Owen, A.M., Schiff, N.D., 2004a. Brain function in coma, vegetative state, and related disorders. Lancet Neurol 3, 537-546. 
Laureys, S., Pellas, F., Van Eeckhout, P., Ghorbel, S., Schnakers, C., Perrin, F., Berre, J., Faymonville, M.E., Pantke, K.H., Damas, F., Lamy, M., Moonen, G., Goldman, S., 2005. The locked-in syndrome : what is it like to be conscious but paralyzed and voiceless? Prog Brain Res 150, 495-511.

Laureys, S., Perrin, F., Bredart, S., 2007. Self-consciousness in non-communicative patients. Conscious Cogn 16, 722-741; discussion 742-725.

Laureys, S., Perrin, F., Faymonville, M.E., Schnakers, C., Boly, M., Bartsch, V., Majerus, S., Moonen, G., Maquet, P., 2004b. Cerebral processing in the minimally conscious state. Neurology 63, 916-918.

Levy, D.E., Sidtis, J.J., Rottenberg, D.A., Jarden, J.O., Strother, S.C., Dhawan, V., Ginos, J.Z., Tramo, M.J., Evans, A.C., Plum, F., 1987. Differences in cerebral blood flow and glucose utilization in vegetative versus locked-in patients. Ann. Neurol. 22, 673-682.

Luaute, J., Fischer, C., Adeleine, P., Morlet, D., Tell, L., Boisson, D., 2005. Late auditory and event-related potentials can be useful to predict good functional outcome after coma. Arch Phys Med Rehabil 86, 917-923.

Lull, N., Noé, E., Lull, J., García-Panach, J., Chirivella, J., Ferri, J., López-Aznar, D., Sopena, P., Robles, M., 2010. Voxel-based statistical analysis of thalamic glucose metabolism in traumatic brain injury: relationship with consciousness and cognition. Brain Inj. 24, 1098-1107.

Majerus, S., Bruno, M.A., Schnakers, C., Giacino, J.T., Laureys, S., 2009. The problem of aphasia in the assessment of consciousness in brain-damaged patients. Prog Brain Res $177,49-61$.

Majerus, S., Gill-Thwaites, H., Andrews, K., Laureys, S., 2005. Behavioral evaluation of consciousness in severe brain damage. Prog Brain Res 150, 397-413. 
Maquet, P., 2010. Understanding non rapid eye movement sleep through neuroimaging. World J Biol Psychiatry 11, 9-15.

Maxwell, W.L., MacKinnon, M.A., Smith, D.H., McIntosh, T.K., Graham, D.I., 2006. Thalamic nuclei after human blunt head injury. J Neuropathol Exp Neurol 65, 478-488.

Menon, D., Owen, A., Williams, E., Minhas, P., Allen, C., Boniface, S., Pickard, J., 1998a.

Cortical processing in persistent vegetative state. Wolfson Brain Imaging Centre Team. Lancet. 352, 200.

Menon, D.K., Owen, A.M., Pickard, J.D., 1999. Response from Menon, Owen and Pickard. Trends Cogn Sci 3, 44-46.

Menon, D.K., Owen, A.M., Williams, E.J., Minhas, P.S., Allen, C.M., Boniface, S.J., Pickard, J.D., 1998b. Cortical processing in persistent vegetative state. Wolfson Brain Imaging Centre Team. Lancet 352, 200.

Monti, M.M., Laureys, S., Owen, A.M., 2010a. The vegetative state. Bmj 341, 292-296. Monti, M.M., Vanhaudenhuyse, A., Coleman, M.R., Boly, M., Pickard, J.D., Tshibanda, L., Owen, A.M., Laureys, S., 2010b. Willful Modulation of Brain Activity in Disorders of Consciousness. N Engl J Med, in press.

Nakase-Richardson, R., Yablon, S.A., Sherer, M., Evans, C.C., Nick, T.G., 2008. Serial yes/no reliability after traumatic brain injury: implications regarding the operational criteria for emergence from the minimally conscious state. J Neurol Neurosurg Psychiatry 79, 216-218.

Nakayama, N., Okumura, A., Shinoda, J., Nakashima, T., Iwama, T., 2006. Relationship between regional cerebral metabolism and consciousness disturbance in traumatic diffuse brain injury without large focal lesions: an FDG-PET study with statistical parametric mapping analysis. J Neurol Neurosurg Psychiatry 77, 856-862. 
Newcombe, V.F., Williams, G.B., Scoffings, D., Cross, J., Carpenter, T.A., Pickard, J.D., Menon, D.K., 2010. Aetiological differences in neuroanatomy of the vegetative state: insights from diffusion tensor imaging and functional implications. J Neurol Neurosurg Psychiatry 81, 552-561.

Noirhomme, Q., Soddu, A., Lehembre, R., Vanhaudenhuyse, A., Boveroux, P., Boly, M., Laureys, S., 2010. Brain connectivity in pathological and pharmacological coma. Front Syst Neurosci 4, 160.

Owen, A.M., Coleman, M.R., Boly, M., Davis, M.H., Laureys, S., Pickard, J.D., 2006. Detecting awareness in the vegetative state. Science $313,1402$.

Owen, A.M., Coleman, M.R., Menon, D.K., Johnsrude, I.S., Rodd, J.M., Davis, M.H., Taylor, K., Pickard, J.D., 2005. Residual auditory function in persistent vegetative state: a combined pet and fmri study. Neuropsychological Rehabilitation 15, 290 - 306.

Owen, A.M., Menon, D.K., Johnsrude, I.S., Bor, D., Scott, S.K., Manly, T., Williams, E.J., Mummery, C., Pickard, J.D., 2002. Detecting residual cognitive function in persistent vegetative state. Neurocase 8, 394-403.

Owen, A.M., Schiff, N.D., Laureys, S., 2009. A new era of coma and consciousness science. Prog Brain Res 177, 399-411.

Phillips, C.L., Bruno, M.A., Maquet, P., Boly, M., Noirhomme, Q., Schnakers, C., Vanhaudenhuyse, A., Bonjean, M., Hustinx, R., Moonen, G., Luxen, A., Laureys, S., 2010. "Relevance vector machine" consciousness classifier applied to cerebral metabolism of vegetative and locked-in patients. Neuroimage, in press.

Plum, F., Schiff, N., Ribary, U., Llinas, R., 1998. Coordinated expression in chronically unconscious persons. Philos. Trans. R. Soc. Lond. B. Biol. Sci. 353, 1929-1933. Posner, J.B., Saper, C.B., Schiff, N.D., Plum, F., 2007. Plum and Posner's diagnosis of stupor and coma, 4th ed. Oxford University Press. 
Qin, P., Di, H., Liu, Y., Yu, S., Gong, Q., Duncan, N., Weng, X., Laureys, S., Northoff, G., 2010. Anterior cingulate activity and the self in disorders of consciousness. Hum Brain Mapp. Raichle, M.E., Snyder, A.Z., 2007. A default mode of brain function: A brief history of an evolving idea. Neuroimage.

Rees, G., Kreiman, G., Koch, C., 2002. Neural correlates of consciousness in humans. Nat Rev Neurosci 3, 261-270.

Ribary, U., Schiff, N., Kronberg, E., Plum, F., Llinas, R., 1998. Fractured brain function in unconscious humans: functional brain imaging using MEG. Neuroimage 7 (Suppl), 106 (Abstract).

Rodriguez Moreno, D., Schiff, N.D., Giacino, J., Kalmar, K., Hirsch, J., 2010. A network approach to assessing cognition in disorders of consciousness. Neurology 75,1871 1878.

Rousseau, M., Confort-Gouny, S., Catala, A., Graperon, J., Blaya, J., Soulier, E., Viout, P., Galanaud, D., Le Fur, Y., Cozzone, P., Ranjeva, J., 2008. A MRS-MRI-fMRI exploration of the brain. Impact of long-lasting persistent vegetative state. Brain Inj. 22, 123-134. Rudolf, J., Ghaemi, M., Haupt, W.F., Szelies, B., Heiss, W.D., 1999. Cerebral glucose metabolism in acute and persistent vegetative state. J. Neurosurg. Anesthesiol. 11, 17-24. Rudolf, J., Sobesky, J., Grond, M., Heiss, W.D., 2000. Identification by positron emission tomography of neuronal loss in acute vegetative state. Lancet 355, 155.

Schiff, N., Ribary, U., Plum, F., Llinás, R., 1999. Words without mind. J. Cogn. Neursci. 11, 650-656.

Schiff, N.D., 1997. Deep brain stimulation method. US Patent.

Schiff, N.D., 2006. Multimodal neuroimaging approaches to disorders of consciousness. J Head Trauma Rehabil. 21, 388-397. 
Schiff, N.D., 2010. Recovery of consciousness after brain injury: a mesocircuit hypothesis. Trends Neurosci 33, 1-9.

Schiff, N.D., Giacino, J.T., Fins, J.J., 2009. Deep brain stimulation, neuroethics, and the minimally conscious state: moving beyond proof of principle. Arch Neurol 66, 697-702. Schiff, N.D., Giacino, J.T., Kalmar, K., Victor, J.D., Baker, K., Gerber, M., Fritz, B., Eisenberg, B., O'Connor, J., Kobylarz, E.J., Farris, S., Machado, A., McCagg, C., Plum, F., Fins, J.J., Rezai, A.R., 2007. Behavioural improvements with thalamic stimulation after severe traumatic brain injury. Nature 448, 600-603.

Schiff, N.D., Plum, F., 1999. Cortical function in the persistent vegetative state. Trends Cogn. Sci. 3, 43-44.

Schiff, N.D., Posner, J.B., 2007. Another "Awakenings". Ann Neurol 62, 5-7.

Schiff, N.D., Ribary, U., Moreno, D.R., Beattie, B., Kronberg, E., Blasberg, R., Giacino, J., McCagg, C., Fins, J.J., Llinas, R., Plum, F., 2002. Residual cerebral activity and behavioural fragments can remain in the persistently vegetative brain. Brain 125, 1210-1234. Schiff, N.D., Rodriguez-Moreno, D., Kamal, A., Kim, K.H., Giacino, J.T., Plum, F., Hirsch, J., 2005. fMRI reveals large-scale network activation in minimally conscious patients. Neurology 64, 514-523.

Schnakers, C., Chatelle, C., Majerus, S., Gosseries, O., De Val, M., Laureys, S., 2010. Assessment and detection of pain in noncommunicative severely brain-injured patients. Expert Rev Neurother 10, 1725-1731.

Schnakers, C., Giacino, J., Kalmar, K., Piret, S., Lopez, E., Boly, M., Malone, R., Laureys, S., 2006. Does the FOUR score correctly diagnose the vegetative and minimally conscious states? Ann Neurol 60, 744-745. 
Schnakers, C., Hustinx, R., Vandewalle, G., Majerus, S., Moonen, G., Boly, M., Vanhaudenhuyse, A., Laureys, S., 2008a. Measuring the effect of amantadine in chronic anoxic minimally conscious state. J Neurol Neurosurg Psychiatry 79, 225-227. Schnakers, C., Perrin, F., Schabus, M., Hustinx, R., Majerus, S., Moonen, G., Boly, M., Vanhaudenhuyse, A., Bruno, M.A., Laureys, S., 2009a. Detecting consciousness in a total locked-in syndrome: An active event-related paradigm. Neurocase, 1-7.

Schnakers, C., Perrin, F., Schabus, M., Majerus, S., Ledoux, D., Damas, P., Boly, M., Vanhaudenhuyse, A., Bruno, M.A., Moonen, G., Laureys, S., 2008b. Voluntary brain processing in disorders of consciousness. Neurology, in press.

Schnakers, C., Vanhaudenhuyse, A., Giacino, J., Ventura, M., Boly, M., Majerus, S., Moonen, G., Laureys, S., 2009b. Diagnostic accuracy of the vegetative and minimally conscious state: clinical consensus versus standardized neurobehavioral assessment. BMC Neurol $9,35$.

Schrouff, J., Perlbarg, V., Boly, M., Marrelec, G., Boveroux, P., Vanhaudenhuyse, A., Bruno, M.A., Laureys, S., Phillips, C., Pelegrini-Issac, M., Maquet, P., Benali, H., 2011. Brain functional integration decreases during propofol-induced loss of consciousness. Neuroimage 57, 198-205.

Sherer, M., Nakase-Thompson, R., Yablon, S.A., Gontkovsky, S.T., 2005. Multidimensional assessment of acute confusion after traumatic brain injury. Arch Phys Med Rehabil 86, 896-904.

Sidaros, A., Engberg, A.W., Sidaros, K., Liptrot, M.G., Herning, M., Petersen, P., Paulson, O.B., Jernigan, T.L., Rostrup, E., 2008. Diffusion tensor imaging during recovery from severe traumatic brain injury and relation to clinical outcome: a longitudinal study. Brain 131, 559-572. 
Silva, S., Alacoque, X., Fourcade, O., Samii, K., Marque, P., Woods, R., Mazziotta, J., Chollet, F., Loubinoux, I., 2010. Wakefulness and loss of awareness: brain and brainstem interaction in the vegetative state. Neurology 74, 313-320.

Smart, C.M., Giacino, J.T., Cullen, T., Moreno, D.R., Hirsch, J., Schiff, N.D., Gizzi, M., 2008. A case of locked-in syndrome complicated by central deafness. Nat Clin Pract Neurol 4, 448-453.

Soddu, A., Boly, M., Nir, Y., Noirhomme, Q., Vanhaudenhuyse, A., Demertzi, A., Arzi, A., Ovadia, S., Stanziano, M., Papa, M., Laureys, S., Malach, R., 2009. Reaching across the abyss: recent advances in functional magnetic resonance imaging and their potential relevance to disorders of consciousness. Prog Brain Res 177, 261-274.

Soddu, A., Vanhaudenhuyse, A., Bahri, M.A., Bruno, M.-A., Boly, M., Demertzi, A., Tshibanda, L., Phillips, C., Stanziano, M., Ovadia, S., Nir, Y., Maquet, P., Papa, M., Malach, R., Laureys, S., Noirhomme, Q., 2011. Identifying the Default Mode component in spatial ICA analyses of patients with disorders of consciousness. Hum Brain Mapp.

Sorger, B., Dahmen, B., Reithler, J., Gosseries, O., Maudoux, A., Laureys, S., Goebel, R., 2009. Another kind of 'BOLD Response': answering multiple-choice questions via online decoded single-trial brain signals. Prog Brain Res 177, 275-292.

Staffen, W., Kronbichler, M., Aichhorn, M., Mair, A., Ladurner, G., 2006. Selective brain activity in response to one's own name in the persistent vegetative state. J Neurol Neurosurg Psychiatry 77, 1383-1384.

Stuss, D.T., Guberman, A., Nelson, R., Larochelle, S., 1988. The neuropsychology of paramedian thalamic infarction. Brain Cogn 8, 348-378.

Tengvar, C., Johansson, B., Sorensen, J., 2004. Frontal lobe and cingulate cortical metabolic dysfunction in acquired akinetic mutism: a PET study of the interval form of carbon monoxide poisoning. Brain Injury 18, 615-625. 
The Multi-Society Task Force on PVS, 1994. Medical aspects of the persistent vegetative state (1). N. Engl. J. Med. 330, 1499-1508.

Tollard, E., Galanaud, D., Perlbarg, V., Sanchez-Pena, P., Le Fur, Y., Abdennour, L., Cozzone, P., Lehericy, S., Chiras, J., Puybasset, L., 2009. Experience of diffusion tensor imaging and $1 \mathrm{H}$ spectroscopy for outcome prediction in severe traumatic brain injury: Preliminary results. Crit Care Med 37, 1448-1455.

Tommasino, C., Grana, C., Lucignani, G., Torri, G., Fazio, F., 1995. Regional cerebral metabolism of glucose in comatose and vegetative state patients. J. Neurosurg. Anesthesiol. 7, 109-116.

Tshibanda, L., Vanhaudenhuyse, A., Boly, M., Soddu, A., Bruno, M.A., Moonen, G., Laureys, S., Noirhomme, Q., 2010. Neuroimaging after coma. Neuroradiology 52, 15-24. Tshibanda, L., Vanhaudenhuyse, A., Galanaud, D., Boly, M., Laureys, S., Puybasset, L., 2009. Magnetic resonance spectroscopy and diffusion tensor imaging in coma survivors: promises and pitfalls. Prog Brain Res 177, 215-229.

Van Der Werf, Y.D., Weerts, J.G., Jolles, J., Witter, M.P., Lindeboom, J., Scheltens, P., 1999. Neuropsychological correlates of a right unilateral lacunar thalamic infarction. J Neurol Neurosurg Psychiatry 66, 36-42.

Van der Werf, Y.D., Witter, M.P., Groenewegen, H.J., 2002. The intralaminar and midline nuclei of the thalamus. Anatomical and functional evidence for participation in processes of arousal and awareness. Brain Res Brain Res Rev 39, 107-140. van Domburg, P.H., ten Donkelaar, H.J., Notermans, S.L., 1996. Akinetic mutism with bithalamic infarction. Neurophysiological correlates. J Neurol Sci 139, 58-65. Vanhaudenhuyse, A., Demertzi, A., Schabus, M., Noirhomme, Q., Bredart, S., Boly, M., Phillips, C., Soddu, A., Luxen, A., Moonen, G., Laureys, S., 2011. Two distinct neuronal 
networks mediate the awareness of environment and of self. J Cogn Neurosci 23, 570578.

Vanhaudenhuyse, A., Noirhomme, Q., Tshibanda, L.J., Bruno, M.A., Boveroux, P., Schnakers, C., Soddu, A., Perlbarg, V., Ledoux, D., Brichant, J.F., Moonen, G., Maquet, P., Greicius, M.D., Laureys, S., Boly, M., 2010. Default network connectivity reflects the level of consciousness in non-communicative brain-damaged patients. Brain 133, 161-171. Vogt, B., Vogt, L., Laureys, S., 2006 Cytology and functionally correlated circuits of human posterior cingulate areas. Neuroimage 29, 452-466.

Vogt, B.A., Laureys, S., 2005. Posterior cingulate, precuneal and retrosplenial cortices: cytology and components of the neural network correlates of consciousness. Prog Brain Res 150, 205-217.

Voss, H.U., Uluc, A.M., Dyke, J.P., Watts, R., Kobylarz, E.J., McCandliss, B.D., Heier, L.A., Beattie, B.J., Hamacher, K.A., Vallabhajosula, S., Goldsmith, S.J., Ballon, D., Giacino, J.T., Schiff, N.D., 2006. Possible axonal regrowth in late recovery from the minimally conscious state. J Clin Invest 116, 2005-2011.

Williams, S., Conte, M.M., Kobylarz, E.J., Hersh, J., Victor, J.D., Schiff, N.D., 2009. Quantitative neurophysiologic characterization of a paradoxical response to zolpidem in a severely brain-injured human subject., Society for Neuroscience Meeting Abstract 541.6.

Xie, G., Deschamps, A., Backman, S.B., Fiset, P., Chartrand, D., Dagher, A., Plourde, G., 2011. Critical involvement of the thalamus and precuneus during restoration of consciousness with physostigmine in humans during propofol anaesthesia: a positron emission tomography study. Br J Anaesth 106, 548-557. 
Zhu, J., Wu, X., Gao, L., Mao, Y., Zhong, P., Tang, W., Zhou, L., 2009. Cortical activity after emotional visual stimulation in minimally conscious state patients. J Neurotrauma 26, 677-688. 